\title{
Generation and Characterization of Skeletal Muscle Cell based Model for GNE Myopathy: Implications in Actin Dynamics
}

\section{Shamulailatpam Shreedarshanee Devi}

Jawaharlal Nehru University

Rashmi Yadav

Jawaharlal Nehru University

Fluencephila Mashangva

Jawaharlal Nehru University

Priyanka Chaudhary

Jawaharlal Nehru University

\section{Shweta Sharma}

Jawaharlal Nehru University

Ranjana Arya ( $\square$ arya.ranjana24@gmail.com )

Jawaharlal Nehru University https://orcid.org/0000-0001-5924-9351

Research article

Keywords: Sialylation, L6 myoblast, SEPT homology recombination, GNE myopathy,actin dynamics

Posted Date: June 30th, 2020

DOl: https://doi.org/10.21203/rs.3.rs-38157/v1

License: (9) (i) This work is licensed under a Creative Commons Attribution 4.0 International License.

Read Full License 


\section{Abstract}

UDP-N-acetyl glucosamine-2 epimerase/ N-acetyl mannosamine kinase (GNE) catalyzes key enzymatic reactions in the biosynthesis of sialic acid. Mutation in GNE gene causes GNE-Myopathy characterized by adult onset muscle weakness and degeneration. GNE is involved in different cellular processes like adhesion, apoptosis, ER stress and autophagy. Lack of appropriate model system limits drug and treatment options for GNE Myopathy as GNE knock out was found to be embryonically lethal. In the present study, we have generated L6 rat skeletal muscle cell-based model system for GNE Myopathy where GNE gene is knocked out at exon 3 using AAV mediated SEPT homology recombination. The cell line was heterozygous for GNE gene with one wild type and one truncated allele as confirmed by sequencing. The phenotype showed reduced GNE epimerase activity with little reduction in sialic acid content. In addition, the GNE knock out cell line revealed altered cytoskeletal organization with disrupted actin filament. The signaling cascade regulating actin dynamics such as Rho A, Cofilin, FAK and Src were altered leading to reduced cell migration in GNE heterozygous cells. Our study indicates possible role of GNE in regulating actin dynamics and cell migration of skeletal muscle cell. The skeletal muscle cell based system offers great potential in understanding pathomechanism and target identification for GNE Myopathy.

\section{Background}

GNE myopathy is a rare neuromuscular genetic disorder caused by mutation in the GNE gene that encodes a bifunctional enzyme catalyzing the rate limiting step in sialic acid biosynthesis. The worldwide prevalence of GNE Myopathy is reported to be 4-21 patients per millionth of population ${ }^{1}$. It is described as familial myopathy with an onset at early adulthood affecting skeletal muscle cells, primarily anterior tibialis sparing quadriceps ${ }^{2}$. More than 200 mutations have been identified to cause the disease with $20 \%$ phenotypic variability associated to genotype ${ }^{3,4}$. Both homozygous and compound heterozygous mutations have been reported in patients with predominantly M743T in Persian Jews, A207V in Japanese, 1618T in Roma Gypsies and V727M in Indian subcontinent ${ }^{1-5}$. A patient with deletion in promoter region of one allele and single mutation in other allele has also been reported with GNE Myopathy ${ }^{6}$. Though it is a slowly progressive disease, progressivity also depends on the nature of biallelic mutation ${ }^{7}$. There are limited therapeutic options, majorly depending on supplementation of sialic acid and its different derivatives- sialyllactose, aceneuramic acid, ManNAc ${ }^{2,8,9}$ (NCT01634750). However, supplementation of sialic acid and administration of aceneuramic acid extended release (Ace-ER) to the patients did not show statistically significant results ${ }^{10}$. Thus, there is utmost need to correlate genotype to phenotype function and develop therapeutic strategies.

Different pathological features are observed in GNE myopathy. Muscle biopsies of GNE myopathy patients revealed muscle fibers of varied sizes, primarily, angular atrophic fibers with rimmed vacuoles in the muscle ${ }^{11}$. The rimmed vacuoles of GNE myopathy are composed of aggregation of protein including $\beta$-amyloid, ubiquitin, a-synuclein, lysosomal proteins, and phosphorylated tau ${ }^{12}$. Hyposialylation of 
different sialylated proteins (NCAM, Integrin) is also found to be one of the pathological features of GNE myopathy ${ }^{13,14}$. Thus, hyposialylation of different glycoconjugates leading to an increase in misfolded proteins forming rimmed vacuoles is the most accepted pathomechanism of GNE myopathy. However, recently many findings suggest alternate role of GNE in other pathways such as cell adhesion, proliferation, mitochondrial dysfunction, UPR pathway, ER stress and apoptosis ${ }^{15-19}$. Also the proteins involved in regulating the cytoskeletal network, integrin pathway, focal adhesion, ERK signaling were found to be upregulated in Gne M743T knock in mice RNA studies ${ }^{3}$. Earlier studies indicated differential expression of a and $y$-actin, Myosin light chain, troponin, tropomyosin-3, Zyxin, Vimentin, Nexilin, and radixin in GNE myopathy muscle samples ${ }^{20}$. Interaction of GNE with CRMP-1 (Collapsin response mediated protein-1), a-actinin-1 and a-actinin-2 suggests a plausible role of GNE in integrin signaling ${ }^{21-}$ 23 . Our previous study also showed hyposialylation of $\beta-1$ integrin and altered focal adhesion and signaling pathway in cells overexpressing mutant GNE or shRNA inhibited GNE ${ }^{16}$. Whether these changes culminate to affect key cytoskeletal elements such as actin remains unknown.

The skeletal muscles are the majorly affected cells in GNEM, and actin proteins tightly regulate muscle cell function. Actin dynamics predominate at the pointed end of thin filaments that extend towards the middle of sarcomere's M-line where they interact with thick filaments to generate contraction ${ }^{24}$. Thus, coordination between sarcomere and other cytoskeletal proteins is critical for the contractile activity of skeletal muscle cell ${ }^{24}$. It is also reported that migration of muscle stem cells promote rapid tissue regeneration during tissue damage and muscle atrophy ${ }^{25}$. Disturbances in actin dynamics had been observed in different myopathic disorders where mutations in actin or actin-binding proteins lead to alteration in assembly and disassembly of actin ${ }^{26,27}$. Thus, actin may play a critical role in muscle cell migration of affected muscles in GNE Myopathy. Whether GNE has a role in regulating cytoskeletal network of skeletal muscle via actin dynamics is not clear.

A major hindrance in understanding GNE function is availability of patient muscle cell and lack of appropriate animal models ${ }^{27}$. A complete GNE knockout was reported to be lethal in mice during early embryogenesis and GNE transgenic mice did not show disease phenotype ${ }^{18,28}$. Different models generated by various groups were found to have varying phenotypes. Sela et al reported that the knock-in mouse model for GNE-M743T mutation showed renal failure, a very different phenotype form as seen in GNE myopathy patients ${ }^{18}$. Further, Schwarzkopf et al reported that the complete knockout of GNE gene in mice model is embryonically lethal ${ }^{29}$. The transgenic mice Gne ${ }^{-/-}$GNED207V and Gne ${ }^{-/-}$GNEV603L exhibited late-onset muscle weakness and atrophy similar to GNE myopathy features ${ }^{30}$. A zebrafish based transgenic model by in situ hybridization with Gne promoter-driven fluorescent was developed that showed significant reduction in locomotor activity, distortion of muscle integrity and reduction in myofibers ${ }^{31}$. Bosch-Morato et al used $\mathrm{C} 2 \mathrm{C} 12$, mouse myoblast cell line, to address the role of sialic acid in $A \beta 1-42$ endocytosis ${ }^{32}$. While all these models have limitations to understand physiological and molecular mechanism underlying the disease, there is stringent need to develop a skeletal muscle cell based model for therapeutic intervention of GNE Myopathy. 
In the present study, we targeted exon 3 of GNE gene in L6 rat skeletal muscle cells which harbors majority of pathologically relevant epimerase domain GNE mutations. GNE gene in Rat (Rattus norvegicus) is located in q22 of chromosome 5. There are two isoforms of GNE in rat which complement to hGNE1 and hGNE2, spanning over 12 exons. The N-terminal epimerase domain catalyzes the epimerization of UDP-N-acetyl glucosamine to $\mathrm{N}$-acetyl mannosamine and the $\mathrm{C}$-terminal kinase domain catalyzes the phosphorylation of $\mathrm{N}$-acetyl mannosamine to $\mathrm{N}$-acetyl- mannosamine-6-P ${ }^{33}$. In order to develop a cell-based model system for GNE Myopathy, we used Adenovirus assisted homology recombination technology along with synthetic exon promoter trap (SEPT) to knock out exon from GNE gene. The SEPT consists of a promoter less Neo resistant gene flanked by two loxP sites. Only successful incorporation at the right site will lead to SEPT gene expression, thereby reducing off-targets. The SEPT can be removed after selection of clone following Cre-recombinase treatment. The GNE knockout cell line was sequence confirmed and validated for GNE enzyme activity. The system was further explored to demonstrate effect of GNE on actin dynamics and signaling pathway affecting muscle cell migration. Our study offers a promising model for understanding pathomechanism and identification of therapeutic targets for GNE Myopathy.

\section{Materials And Methods}

\section{Cell culture of L6 cell line}

L6 cells are myoblast cells and were maintained always below 50\% confluency to avoid the cells to differentiate muscle cells. Cells were trypsinized with $1 \mathrm{ml} / 2 \mathrm{ml}$ of trypsin- EDTA form T-25/T-75 culture flask. Cells were seeded in cell density of 1:20-40 ratio.

\section{Genomic DNA isolation}

Cells cultured in $100 \mathrm{~mm}$ dish were trypsinized and washed with 1X PBS. Cells were counted using haemocytometer and $5 \times 10^{6}$ cells were centrifuged at $1500 \mathrm{rpm}$ for $5 \mathrm{~min}$ in a microcentrifuge tube at room temperature. The supernatant was discarded, and the cells were resuspended in $200 \mu \mathrm{l}$ X PBS. Genomic DNA isolation was done using QIAamp DNA Blood Mini Kit (Qiagen, Germany) according to the manufacturer's instructions (Qiagen, Germany). The collected DNA was stored at $-20^{\circ} \mathrm{C}$.

\section{Amplification of homology arms from genomic DNA}

For amplification of homology arms, primer designing is one of the critical parts. The primers should be in intron portion of the gene that flanks the exon with size approximately $>800 \mathrm{bp}$ for successful recombination. The left homology arms primer should contain a Notl site at $3^{\prime}$ end for ligation with MCS vector of rAAV shuttle and a non-cutter restriction site at $5^{\prime}$ end compatible for SEPT. The right homology arms also follow the same but with alteration in the position of restriction sites, i.e., Notl site at the $5^{\prime}$ end while the 3' end possesses restriction site compatible for SEPT. Primers for Epimerase left homology arm is -L-HA (5'-GCGGCCGCCCTGAGTCAGCACATTACAGAGACG-3' and 3'-

TCTAGAAGCGCAGCTGTCCCCCCACCCCATG-5') and primers for Epimerase Right homology arm is - R-HA 

5 .

\section{PCR condition for amplification of homology arms}

Table 1

PCR condition for amplification of homology arms

\begin{tabular}{|llll|}
\hline Cycle no. & Denaturation & Annealing & Extension \\
\hline 1 & $98^{\circ} \mathrm{C}-5 \mathrm{~min}$ & & \\
$2-5$ & $98^{\circ} \mathrm{C}-20 \mathrm{sec}$ & $70^{\circ} \mathrm{C}-20 \mathrm{sec}$ & $72^{0} \mathrm{C}-25 \mathrm{sec}$ \\
$6-9$ & $98^{\circ} \mathrm{C}-20 \mathrm{sec}$ & $65^{0} \mathrm{C}-20 \mathrm{sec}$ & $72^{0} \mathrm{C}-25 \mathrm{sec}$ \\
$10-13$ & $98^{\circ} \mathrm{C}-20 \mathrm{sec}$ & $60^{\circ} \mathrm{C}-20 \mathrm{sec}$ & $72^{0} \mathrm{C}-25 \mathrm{sec}$ \\
$14-43$ & $98^{\circ} \mathrm{C}-20 \mathrm{sec}$ & $58^{\circ} \mathrm{C}-20 \mathrm{sec}$ & $72^{0} \mathrm{C}-25 \mathrm{sec}$ \\
& & & $72^{\circ} \mathrm{C}-5 \mathrm{~min}$ \\
\hline
\end{tabular}

\section{Cloning of homology arms in pJET 1.2/blunt vector}

The PCR amplified homology arms for exon 3 were gel eluted using Gel Elute (Qiagen) and the eluted samples were used as insert and ligated in pJET1.2/blunt vector (Thermo Scientific) following the manufacturing protocol. Briefly, amplified samples were ligated using T4 DNA ligase with a molar ratio of 1:5 (vector to insert) and incubated in water bath at $16^{\circ} \mathrm{C}$ overnight. The ligated samples were transformed in XL1-blue competent cells and clones were selected each for left homology arm and right homology arm. The selected clones were digested with Not1 and Xba1 for left homology arm and Not1 and Sal1 for the right homology arm. The digested samples were run on $1 \%$ agarose gel. Clones were selected and sequenced using Sanger sequencing.

\section{Cloning of SEPT, left and right homology arm with pAAV- MCS vector}

After the sequence confirmation of homology arms, the left homology arm and right homology arm were digested with Not1/Xba1 (Takara Bio, Japan) and Sal1/Not1 (Takara Bio, Japan) respectively. The $1 \mathrm{~Kb}$ fragment was gel eluted. Further, pAAV- SEPT acceptor plasmid was digested with Xba1 and Sal1 restriction enzymes and pAAV-MCS vector with Not1. The digestion of pAAV-SEPT acceptor generated 2 fragments- $3 \mathrm{~Kb}$ (vector backbone) and $2 \mathrm{~Kb}$ (SEPT) and the digestion of pAAV-MCS vector with Not1 generated $3 \mathrm{~Kb}$ (vector backbone) and $1.6 \mathrm{~Kb}$ fragment. The $2 \mathrm{~Kb}$ fragment SEPT and $3 \mathrm{~Kb}$ fragment pAAV-MCS vector backbone was gel eluted. The left and right homology arms and SEPT constructs were ligated to PAAV-MCS vector backbone using T4 DNA ligase at $16^{\circ} \mathrm{C}$ overnight. The ligated DNA was transformed in XL1-Blue competent cells.

\section{Screening of shuttle vector}


After the transformation, the clones were picked, and plasmid DNA was isolated for restriction digestion analysis. The DNA was digested with EcoR1 to check for $1 \mathrm{~Kb}$ DNA fragment fall out. Further confirmation of the clones was done by digesting them with Nde1 to yield a product of $2.8 \mathrm{~Kb}$ and $4 \mathrm{~Kb}$. This vector was called Epimerase shuttle vector or pAAV-GNE-EP-SEPT.

\section{Generation of AAV virus particle incorporating Epimerase shuttle vector}

AAV virus particle was generated by transfecting Epimerase shuttle vector harboring SEPT and Epimerase homology arms along with AAV- Helper vector and AAV-RC vector in AAV293 cells using calcium phosphate method. Briefly, AAV293 cells were grown in DMEM. $10 \mu \mathrm{g}$ of each DNA (Epimerase shuttle vector, AAV-Helper vector and AAV-RC vector) was mixed with $1 \mathrm{ml}$ of $0.3 \mathrm{M} \mathrm{CaCl}_{2}$. The DNA-CaCl 2 was mixed with $2 \times$ BES [N,N-bis (2-hydroxyethyl)-2-aminoethanesulfonic acid, Sigma Aldrich] buffer in the ratio $1: 1$. DNA-CaCl $2-B E S$ mixture was added to the $70-80 \%$ confluent cells (in $5 \mathrm{ml}$ DMEM) in dropwise manner while swirling the cells. The media was changed after $6 \mathrm{~h}$ post-transfection with $10 \mathrm{ml}$ DMEM and grown for $72 \mathrm{~h}$. After $72 \mathrm{~h}$, viral plague was observed under microscope. In the negative control plate, there was no formation of viral plague while AAV-Epimerase transfected with Epimerase shuttle vector, AAV-RC and AAV-Helper show visible plague formation with cells floating in the medium.

\section{Infection of L6 cells with the AAV-Epimerase virus}

Viruses generated in AAV-293 cells were harvested using the freeze-thaw method and centrifuged to remove cell debris ${ }^{34}$. L6 cells were grown in 6 well plates till $50 \%$ confluency. Cells were washed with prewarmed HBSS (Hank's Balanced Salt Solution, GIBCO) buffer at $37^{\circ} \mathrm{C}$ and infected with $300 \mu \mathrm{l}$ of AAVepimerase virus (added dropwise). $1 \mathrm{ml}$ DMEM (pre-warmed at $37^{\circ} \mathrm{C}$ ) was added and incubated for $3 \mathrm{~h}$. Post infection, $2 \mathrm{ml}$ of DMEM media was added to the cells and further incubated for $48 \mathrm{~h}$. After $48 \mathrm{~h}$, cells were trypsinized and 500 cells were seeded to five 96 well plates supplemented with $800 \mu \mathrm{g} / \mathrm{ml}$ of G418 drug. Single cell colonies were transferred to 24 well plates and grown in DMEM supplemented with G418 drug which was further transferred to 6 well plate. G418 resistant clones were further screened for SEPT insertion in the GNE gene.

\section{Screening of clones with the PCR method}

Clones obtained after G418 drug $(600 \mu \mathrm{g} / \mathrm{ml})$ treatment were grown in 6 well plates in DMEM with G418. Genomic DNA was isolated using QIAamp DNA Blood Mini kit (Qiagen) followed by PCR using the primers 3 and 4 (5'-CATGGTGACCCCGTTACTTTCTTGCATCC-3' and 5'-

CCACAATCACACAGTGGCTCCTGACTAT-3') that encompasses SEPT and left homology arm. Further, PCR using primers 1 and 2 (5'-GGGACTTAGGCTATAGTGTGGTAC-3' and 5'-

GGAGCTCTGTGAGTTCAAAGCTAG-3') that covers both the homology arms and SEPT was conducted with positive clone. The PCR products were run on $1 \%$ agarose gel.

\section{Confirmation of SEPT incorporation replacing Exon 3}


The SEPT incorporation at the correct site of rat GNE gene was further confirmed by Sanger Sequencing using primers 1 and 2 (Eurofins, India). The BLAST analysis was done using sequence obtained with rat GNE sequence and SEPT.

\section{Excision of SEPT with Cre-recombinase}

SEPT contains two loxP sites at both the end allowing the SEPT to be removed using Cre-recombinase that recognizes loxP site. Clones with SEPT incorporation (GNE-SEPT) were subjected to infection with Ad-Cre virus (Vector Biolabs, USA) with $10^{7}$ plaque forming units, added to a $15 \mathrm{ml}$ Falcon tube containing $2 \mathrm{ml}$ of DMEM media. The mixture was mixed by pipetting. The media from the cells was removed and $A d$-Cre solution was added and incubated for $24 \mathrm{~h}$. After successful infection cells were trypsinized and counted. 500 cells were transferred to five 96 well plates in DMEM. Single clones were picked and transferred to 24 well plates in duplicate. A set of plates were treated with $800 \mu \mathrm{g} / \mathrm{ml}$ of G418 drug while the other set was grown without G418. Those cells which die after G418 drug were chosen as positive cells from the replica plate. 38 clones were selected, and genomic DNA was isolated. PCR amplification using primers 1 and 2 was done to check the excision of SEPT fragment from the GNESEPT clones.

\section{Sequence confirmation of heterozygous knockout of GNE Exon 3}

After confirmation of the successful excision of SEPT form the GNE-SEPT cells, we use the positive clone named as SKM-GNEHz (Skeletal Muscle-GNE Heterozygous) cell for further confirmation of sequence. Primers 1 and 2 were used for sequence confirmation.

\section{Cell lines and preparation for whole cell lysate}

Cells were seeded in DMEM media followed by incubation in DCCM media for $24 \mathrm{~h}$. As sialic acid is a component of serum, DCCM (Biological Industries), serum-free media was used to avoid sialic acid uptake from the medium. The cells were lysed using $1 \mathrm{ml}$ of RIPA lysis buffer containing $20 \mathrm{mM}$ Tris- $\mathrm{HCl}$ (pH-7.5), 1\% NP-40 (Sigma Aldrich), 150 mM NaCl, 1 mM EDTA and protease inhibitor cocktail (Sigma Aldrich). The cell lysates were incubated for $45 \mathrm{~min}$ on ice. Cells were collected and centrifuged at $13000 \mathrm{rpm}$ to remove cell debris. The supernatant was collected, and protein content was estimated using Bradford reagent (Sigma Aldrich).

\section{Antibodies}

Primary antibodies for $\beta$-actin (1:2000 dilution), RhoA (1:1000), Cofilin (1:1000 dilution), GAPDH (1:2000), GNE (1:1000), FAK (1:2000 dilution), Src (1:2000 dilution) and p-FAK (1:1000 dilution) and p-Src (1:1000 dilution) were purchased from Santa Cruz Biotechnology, USA and Cell Signaling Technology, USA. HRPconjugated secondary antibodies were used with dilution of 1:5000 (Santa Cruz Biotechnology).

\section{RNA extraction}


Total RNA was isolated from the cells grown in 6 well plate using One-step RNA isolation reagent (Bio basic Inc). Briefly, cells were washed with $1 X$ PBS and lysed for 5 min with One-step RNA isolation reagent (Bio Basic, Inc, Canada). $200 \mu$ of chloroform was added to the mixture followed by mixing and centrifuged at $12000 \mathrm{x}$ g. The upper aqueous layer was collected and $500 \mu \mathrm{l}$ of isopropanol was added followed by mixing the solution. The mixture was centrifuged, and the supernatant was discarded while the collected pellet was washed with $80 \%$ ethanol and centrifuged at $12000 \mathrm{xg}$ for $10 \mathrm{~min}$. The pellet was dried at room temperature and dissolved in $30 \mu \mathrm{l}$ of RNase free water supplemented with Ribolock RNase inhibitor (Thermo Scientific).

\section{cDNA synthesis}

cDNA was synthesized using $10 \mu \mathrm{g}$ of RNA using RevertAid Reverse Transcriptase kit (Thermo Scientific) following the manufacturer's manual. Briefly, the reaction was incubated at $25^{\circ} \mathrm{C}$ for $5 \mathrm{~min} ; 40^{\circ} \mathrm{C}$ for $60 \mathrm{~min} ; 70^{\circ} \mathrm{C}$ for $10 \mathrm{~min}$ in a Thermocycler (Applied Biosystem, USA).

\section{Quantitative Real Time-PCR for GNE}

Total RNA was extracted from the cells grown in 6 well plate by using One step RNA reagent (Bio Basic Inc., Canada) according to manufacturer's instructions, further $2 \mu \mathrm{g}$ of total RNA was treated with DNase I (Thermo Scientific) to remove DNA contamination. $10 \mu \mathrm{g}$ of total RNA was reverse transcribed to cDNA using RevertAid Reverse Transcriptase kit (Thermo Scientific) as recommended in manufacturer's manual. A control PCR amplification reaction of GAPDH was carried out using prepared CDNA as template to confirm the cDNA synthesis. For quantitative real time PCR, specific primers with primer sequence; forwardprimer'5'GAGAAGAACGGGAATAACCGGAAG 3' and reverseprimer3'GATGAGCGTCACAAAGTTCTCCTG 5'along with KAPA SYBR fast qPCR master mix and low ROX dye were used to amplify for GNE EP-mRNA. Quantitative real time PCR was performed at PCR cycling condition of denaturation at $95^{\circ} \mathrm{C}$ for $30 \mathrm{sec}$; annealing at $58^{\circ} \mathrm{C}$ for $20 \mathrm{sec}$ and extension at $72^{\circ} \mathrm{C}$ for $30 \mathrm{sec}$ for 25 cycles by using Mx3000P qPCR System(Agilent). relative mRNA expression was normalized to internal control (GAPDH).

\section{Determination of the Sialic acid content}

Sialic acid levels were measured by an adaptation of the periodate/resorcinol method ${ }^{35}$. In brief, $1 \times 10^{6}$ cells of various recombinant exon 3 GNE knockout and L6 control cell lines were incubated in DCCM media for $24 \mathrm{~h}$, and then resuspended in $100 \mu \mathrm{l}$ of PBS after harvesting. Cells were lysed by three freeze/thaw cycles, and protein was estimated using Bradford assay. Equal amount of protein from each cell lysate was oxidized by the addition of $1 \mu \mathrm{l}$ of $0.4 \mathrm{M}$ periodic acid followed by incubation at $4{ }^{\circ} \mathrm{C}$ (for total sialic acid) and $37^{\circ} \mathrm{C}$ (for conjugated sialic acid) for $1.5 \mathrm{~h}$ and $15 \mathrm{~min}$ boiling in $100 \mu \mathrm{l}$ of $6.0 \%(\mathrm{w} / \mathrm{v}$ ) resorcinol/2.5 mM CuSO4/44\% (v/v) concentrated $\mathrm{HCl}$. After cooling, $100 \mu \mathrm{l}$ of t-butyl alcohol was added to each sample. The samples were vortexed and centrifuged at $15,700 \mathrm{~g}$ for $5 \mathrm{~min}$ to remove insoluble cell debris. Supernatants were separated from the pellets, and OD readings were taken at $630 \mathrm{~nm}$. A standard curve was generated from known concentrations $(0,5,10,25,50,100 \mu \mathrm{M})$ of sialic acid (Sigma Aldrich), and the sialic acid content of cells was calculated by comparison with the standard curve. 


\section{Supplementation with Sialic Acid}

Cells were grown in DMEM media for $16 \mathrm{~h}$ followed by supplementation with $5 \mathrm{mM}$ sialic acid in DCCM for $24 \mathrm{~h}$.

\section{Epimerase activity assay}

The UDP-GIcNAc 2-epimerase activity was determined as described before ${ }^{36}$. Briefly, variable amounts of protein were mixed with $45 \mathrm{mM} \mathrm{Na}_{2} \mathrm{HPO}_{4}, \mathrm{pH} 7.5,10 \mathrm{mM} \mathrm{MgCl}_{2}$, and $1 \mathrm{mM}$ UDP-GlcNAc in a final volume of $40 \mu$. The reaction was performed at $37^{\circ} \mathrm{C}$ for at least $30 \mathrm{~min}$ and stopped by boiling for $1 \mathrm{~min}$. After centrifugation at 20,000 $\mathrm{xg}$ for $1 \mathrm{~min}$, the released ManNAc was detected with the Morgan-Elson method $^{37}$. In brief, $30 \mu \mathrm{l}$ of the sample was mixed with $6 \mu \mathrm{l}$ of $0.8 \mathrm{M}$ borate, $\mathrm{pH} 9.1$, and boiled for $3 \mathrm{~min}$. $160 \mu \mathrm{l}$ of DMAB solution ( $1 \%(\mathrm{w} / \mathrm{v})$ 4-dimethylamino benzaldehyde in acetic acid, $1.25 \% 10 \mathrm{M} \mathrm{HCl}$ ) was added and the sample was incubated at $37^{\circ} \mathrm{C}$ for $30 \mathrm{~min}$. The absorbance was read at $578 \mathrm{~nm}$. One unit of enzyme activity was defined as the formation of $1 \mu \mathrm{mol}$ ManNAc per min at $37^{\circ} \mathrm{C}$. Specific activity was expressed as milli units per milligram protein.

\section{Preparation of G-actin and F-actin fraction}

Cells were cultured in $100 \mathrm{~mm}$ dishes in DCCM media for $24 \mathrm{~h}$. Cells were washed with PBS buffer and lysed with $1 \mathrm{ml}$ of F-actin stabilizing lysis solution containing $50 \mathrm{mM}$ - PIPES 6.9pH, $50 \mathrm{mM} \mathrm{NaCl}, 5 \mathrm{mM}$ $\mathrm{MgCl}_{2}, 5$ mM EGTA, 5\% glycerol, 0.1\% Triton X-100, 0.1\% Tween-20, 0.1\% NP-40, 0.1\% 2-mercaptoethanol, $1 \mathrm{mM}$ ATP, protease inhibitor cocktail for $45 \mathrm{~min}$ on ice. The cells were scraped and centrifuged at $1,00,000 \times \mathrm{g}$ for $1 \mathrm{~h}$. The supernatant containing the G-actin fraction was collected while the pellet was dissolved in $1 \mathrm{ml}$ of chilled water containing $1 \mathrm{mM}$ cytochalasin $\mathrm{D}$ and incubated for $1 \mathrm{~h}$. The pellet was centrifuged at 13,000 rpm for $30 \mathrm{~min}$ and the supernatant were collected for F-actin fraction. Equal volumes of G-actin and F-actin fraction were subjected for immunoblot analysis using an anti- $\beta$-actin antibody ( $\beta$-actin (C4), Santacruz Biotechnology, USA) and imaging was done by Enhanced Chemiluminescence (ECL) using ChemiDoc Imaging Systems, Bio-Rad Laboratories. The F/G actin ratio was determined by densitometry of the immunoblots.

\section{TRITC-phalloidin staining}

Cells were grown in tissue culture plates containing sterile coverslip in DCCM media for $24 \mathrm{~h}$. Cells were, then, fixed with 3.7\% paraformaldehyde and stained with 1:300 dilution of TRITC- Phalloidin (Sigma Aldrich) and $1 \mu \mathrm{g} / \mu \mathrm{l}$ of Hoechst nuclear stain for $30 \mathrm{~min}$ and $10 \mathrm{~min}$, respectively. Cells were mounted on slides using DABCO (Sigma Aldrich). Images were acquired at $555 \mathrm{~nm}$ in Olympus FluoView FV1000 ver1.7. Quantitative analysis was done using Olympus FluoViewFV1000 ver1.7a software and Image J software.

\section{Wound Healing assay}

L6 myoblast cells were counted and $0.5 \times 10^{5}$ cells were seeded in each chamber in IBIDI inserts followed by incubation at $37^{\circ} \mathrm{C}$ for $24 \mathrm{~h}$ in DCCM media. The inserts were removed, and cells were washed with 
DCCM media. $500 \mu \mathrm{l}$ DCCM media was added and images were captured at $20 \mathrm{X}$ magnification in Zeiss Axis Vert. A1 inverted microscope (Carl Zeiss AG, Germany).

\section{Results}

A major limitation in understanding the pathophysiology of GNE Myopathy is the availability of appropriate model system for the study. A complete GNE knockout in mice model was embryonically lethal and transgenic mice model did not represent the disease phenotype ${ }^{28,29}$. Thus, understanding GNE function and identification of appropriate drug targets has been a big challenge. Here, we describe a rat skeletal muscle cell-based model system with GNE exon deletion depicting the phenotype similar to GNE mutant cells. This model system can potentially be used for understanding the pathophysiology and drug screening for GNE function.

In the present study, we aim to generate a GNE exon knockout in L6 rat skeletal muscle cell line using Adenovirus assisted SEPT vector based homology recombination technology as shown in Fig. $1^{38}$. SEPT stands for Synthetic Exon Promoter Trap. It consists of IRES (internal ribosomal entry site) and a promoterless Neomycin resistance gene, flanked by loxP sites (Fig. 2a). SEPT uses the promoter of the target gene after successful recombination, making it more efficient and reducing the chance of off-target recombinations ${ }^{38}$. The presence of IOXP sites in SEPT also allows removal of SEPT component after recombination using Cre-recombinase, leaving the gene intact without the targeted exon (Fig. 2b). Exon 3 represents epimerase domain region where majority of pathologically relevant mutations have been identified in GNE Myopathy.

The Rat GNE gene (Gene ID: 114711) of L6 skeletal muscle cell line is used as target in the study. It encodes two isoforms hGNE1 (753 amino acids) and hGNE2 (722 amino acids). In rat GNE gene, exon 3 (19615 bp-20066 bp) represents the epimerase exon that has the highest frequency of pathologically relevant GNE mutations. Generation of exon 3 knockouts in L6 rat skeletal muscle cells required cloning of homology arms in pJET1.2 blunt vector. Homology arms were amplified from the intronic region upstream (left homology arm) and downstream (right homology arm) of exon 3 of rat GNE gene as shown in Fig. 2b. The desired PCR bands of approx. $1 \mathrm{~Kb}$ from either homology arms were cloned in pJET/1.2 vector and sequence verified (Figure S1, S2 and S3). Following cloning of homology arms, a shuttle vector for exon 3 was generated in pAAV-MCS vector (Agilent Technologies) with SEPT fragment flanked by both the arms. The epimerase shuttle vector or GNE-EP-SEPT vector was confirmed by restriction mapping (Fig. 2C). Then, an AAV-virus carrying shuttle vector was generated in AAV 293 cells by transfecting the cells with the shuttle vector, RC vector and Helper vector (Agilent Technologies). Visible plaques were obtained from AAV293 cells and virus particles were harvested post-infection to determine the titer (Figure S4). L6 rat skeletal muscle cells were infected with AAV-virus particle carrying shuttle vector (GNE-EP-SEPT) and screened with G418 drug (800 $\mu \mathrm{g} / \mathrm{ml}$, Ameresco Company). G418 resistant clones were, further, screened by PCR for SEPT insertion in GNE via homologous recombination. As shown in Fig. 2d, the desired band confirming SEPT inserting of molecular weight $3.3 \mathrm{~Kb}$ was observed in clone 3. This clone was further confirmed by sequencing using Sanger Method (Figure S5). 
Further, the positive cells with SEPT insertion were infected with Ad-Cre virus (Vector Laboratory) harboring Cre-recombinase enzyme that will remove SEPT region using loxP sites. The screening of SEPT negative cells was done by replica plating as loss of SEPT will cause the cells to be G418 sensitive. The positive clones from replica plates were screened for exon 3 knock out by PCR amplification (Fig. 2d). The PCR positive clones were further confirmed by sequencing for loss of exon 3 in one of the alleles (Figure S6). The sequencing data confirmed the presence of both the alleles, wild type GNE with exon 3 (2.2 Kb fragment) and truncated GNE with loss of exon 3 (1.8 Kb fragment). This indicated that we generated a heterozygous skeletal muscle cell line with one wild type GNE allele and other allele knocked out at exon 3 of GNE. This cell line was labeled as SKM-GNEHz (heterozygous for GNE).

\section{Characterization of GNE Exon-3 knockout cell line (SKM-GNEHz)}

The effect of exon 3 deletion on GNE transcript and protein production was analyzed in the heterozygous cell line (SKM-GNEHz). For transcript analysis, mRNA from wild type GNE and SKM-GNEHz cell lines was isolated and subjected to RT-PCR using primers 5' GAGAAGAACGGGAATAACCGGAAG 3' and 3' GATGAGCGTCACAAAGTTCTCCTG 5' spanning from exon 2 and exon 9 of wild type GNE. As shown in Fig. 3a, the mRNA from wild type GNE gene would yield a product of $1.6 \mathrm{~Kb}$ while from exon-3 knocked out GNE gene would yield a product of $1.1 \mathrm{~Kb}$. The amplified PCR fragments were analyzed on $1 \%$ agarose gel. As shown in Fig. 3b, only one fragment corresponding to $1.6 \mathrm{~Kb}$ was observed in SKMGNEHz similar to wild type GNE. This indicates that transcript corresponding to knock out allele may not be synthesized, probably due to improper splicing. However, the densitometry analysis of the mRNA band indicates that there is approx. $45 \%$ reduction in the transcript level of GNE (Fig. 3b) in SKM-GNEHz as compared to wild type L6 suggesting that knockout of GNE from an allele resulted in reduction in GNE transcript level. In order to determine the copy number of GNE gene in SKM-GNEHz, real time PCR analysis was done using primers indicated in Materials and Methods. The $C_{t}$ value comparison showed 2-fold reduction in GNE levels for SKM-GNEHz compared to wild type GNE cell line (Fig. 3c). Our study suggests a 2-fold reduction in GNE copy number in SKM-GNEHz, thereby indicating production from only one allele. The protein expression levels of GNE were analyzed in SKM-GNEHz compared to wild type GNE by immunoblot analysis using specific antibody. As shown in Fig. 3d, only single protein band corresponding to wild type GNE (approximately, $79 \mathrm{kDa}$ ) was observed in SKM-GNEHz. This suggests that no protein was, probably, translated from knock out allele. Whether these changes in GNE gene, transcript and protein levels are significant to affect GNE function needs to be investigated further.

Recently, Chakravorty et a/ reported that a patient with a deletion in the promoter of one allele GNE and having a single mutation in the other allele showed GNE myopathy phenotype ${ }^{6}$. This shows that heterozygous knockout or non-functional one allele may lead to GNE Myopathy. Even though there were no changes in the transcript and protein size of GNE in the heterozygous knockout SKM-GNEHz, we further investigated whether GNE knockout in one allele could result in a phenotype. We determined the sialic acid content of SKM-GNEHz as compared to wildtype L6 rat muscle cells. Cells were seeded in $100 \mathrm{~mm}$ dishes and grown in DCCM media supplemented with $4 \mathrm{mM}$ of L-glutamine for $24 \mathrm{~h}$. The sialic acid content was determined by the resorcinol-periodate method as described before. Approximately, $20 \%$ 
reductions in the conjugated sialic acid and $10 \%$ reduction in total sialic acid content was observed in SKM-GNEHz cells as compared to the wild type L6 skeletal muscle cells (Fig. 4a). Further, sialic acid supplementation of cells restored total sialic acid content in the SKM-GNEHz cells (Fig. 4b). This study suggests that heterozygous GNE knock out cells do not show drastic reduction in sialic acid content. Whether one wild type allele is sufficient for sialic acid production in the cell needs to be explored further.

Although no significant reduction in the sialic acid content of GNE heterozygous knockout was observed, it was important to assess the effect of GNE knock out on its activity. For this purpose, the epimerase activity of GNE was determined in SKM-GNEHz cells. Approximately, $60 \%$ reduction in epimerase enzyme activity of SKM-GNEHz was observed as compared to wildtype L6 cells (Fig. 4c). Significant reduction in GNE enzyme activity could lead to altered cellular functions mediated by GNE. This study would help us identify the potential role of GNE in the muscle cell.

\section{Effect of GNE exon 3 knockout on actin dynamics in rat skeletal muscle cell}

Role of actin, being a key cytoskeletal component, is significant in muscle contraction, regeneration and migration. While sliding of thin actin filament over thick myosin filament is important for muscle contraction, assembly and disassembly of actin filament provides driving force for cell migration ${ }^{39}$. Maintenance of monomer G-actin and filamentous F-actin pool is tightly regulated inside the cell ${ }^{40,41}$. In striated muscle, the sarcomeric actin filaments undergo dynamic turnover without altering the sarcomeric structure ${ }^{42}$. Further, actin dynamic is critical for myoblast cell migration, and myoblast fusion vital for muscle regeneration ${ }^{43,44}$. In GNE myopathy, muscle regeneration is severely affected and actin may have a role in regulating this phenomenon. Therefore, we investigated the change in actin dynamics level, by studying the levels of G-actin and F-actin in SKM-GNEHz cells. G-actin and F-actin pools were isolated from L6 skeletal muscle cells and SKM-GNEHz and subjected to SDS-PAGE analysis followed by immunoblotting with specific antibodies. As shown in Fig. 5a, G-actin levels were found to be higher in SKM-GNEHz compared to wild type muscle cells. Also F/ G-actin ratio was significantly reduced in SKMGNEHz cell line compared to control (Fig. 5a). This study suggests that polymerization of actin monomers (G-actin) to F-actin is inhibited in GNE-SKMHz cells.

The alteration in actin pattern was further confirmed by staining with phalloidin using confocal microscopy. The cells were grown in DCCM media for $24 \mathrm{~h}$ followed by TRITC-phalloidin staining as described in Material \& Methods. Confocal images showed disrupted F-actin pattern in SKM-GNEHz cell line compared to control (Fig. 5b). F-actin filament was shorter and thinner in SKM-GNEHz while wild type L6 cells showed longer and striated actin pattern. This is the first report to demonstrate the disruption of actin cytoskeletal organization in skeletal muscle cell with altered GNE function.

\section{GNE exon-3 knockout affects RhoA signaling and its effector molecule}

Rho GTPases are small molecules that play central role in regulating actin assembly ${ }^{45}$. The activity of RhoA is upregulated in heterotopic ossified muscle cells in DMD (Duchenne Muscular Dystrophy) leading 
to weakness and degeneration of muscle cells ${ }^{46}$. RhoA is also localized in the focal adhesion involved in

triggering downstream integrin signaling leading to actin assembly and disassembly ${ }^{47,48}$. We also investigated the levels of RhoA in SKM-GNEHz as compared to wild type control cells. Immunoblot analysis with anti-RhoA antibody showed that expression level of RhoA protein was upregulated in SKMGNEHz cells as compared to wild type L6 cells (Fig. 6a). Densitometric analysis of immunoblots revealed statistically significant increase in RhoA levels in SKM-GNEHz cells compared to control. Downstream cascade of RhoA upregulation relate to upregulation of ROCK that further activates LIMK which in turn phosphorylates Cofilin. Phosphorylation of Cofilin inactivates its actin severing function, thereby inhibiting F-actin depolymerization. In our study, we found increased phosphorylation of Cofilin in SKMGNEHz cell lines compared to control cells (Fig. 6b) suggesting inactivation of Cofilin. This inhibits actin severing and may cause slow turn-over of actin pool.

The signaling molecules for actin formation upstream of RhoA involve Src Tyrosine kinases and FAK (focal adhesion kinases). Src is involved in stimulation of initial actin filament nucleation and regulates the rate of turnover of actin filament ${ }^{49}$. We observed approximately $28 \%$ reduction in Src activation in SKM-GNEHz cells line compared to control cells (Fig. 6c). This suggests down regulation of Src activity that may have significant effects in actin assembly in SKM-GNEHz cells.

Expression and phosphorylation of FAK regulates the myoblast differentiation, muscle fiber formation and muscle size ${ }^{50,51}$. FAK is required for muscle cell migration and F-actin formation ${ }^{52}$. Reduced $p$ FAK/FAK ratio was observed in GNE heterozygous cell line compared to control suggesting implications to FAK activation (Fig. 6d). Our study indicates that GNE may have a role in regulating signaling molecules of actin assembly pathway and alteration in GNE activity may significantly disrupt the cytoskeletal organization via actin.

\section{Effect of GNE exon - 3 knockout in L6 myoblast cell migration}

Myoblast cell migration is critical for muscle cell regeneration and myoblast fusion critical for muscle differentiation. Migration of cell is directly regulated by actin dynamics. During the process of cell migration, actin polymerization provides the required force for cell to move forward. Migration of cells involves four different steps- protrusion of lamellipodia in the front, focal adhesion protein recruitment, retraction of the rare and disassembly of the focal adhesion from the rare ${ }^{53,54}$. In the present study, we found that F/G actin is reduced in SKM-GNEHz as compared to $L 6$ wild type cells. To investigate whether alteration in actin dynamics in SKM-GNEHz affects the cell migration, we conducted wound healing assay using cell culture inserts and followed wound closure for $24 \mathrm{~h}$ as mentioned in Material and Methods. As shown in Fig. 7, cell migration was drastically reduced in SKM-GNEHz compared to L6 cells. There was approx. $60 \%$ reduction in cell migration. This finding suggests that GNE may play a critical role in regulating cell migration property of muscle cell and may contribute to slow regeneration of muscle cell in GNE myopathy.

\section{Discussion}


GNE Myopathy is a rare neuromuscular disorder with little understanding about the molecular mechanism of the disease. GNE is primarily involved in sialic acid biosynthesis and hyposialylation is considered to be the cause of the disease. However supplementation with sialic acid and its precursors only slows the disease progression and does not provide a cure. Simultaneously studies suggest an alternate role of GNE in other cellular processes that may be hampered in patient muscle cells due to mutations in GNE. Non-availability of appropriate model system restricts the understanding about role of GNE in muscle cell function.

In the present study, we aimed to develop a rat skeletal muscle cell based system with GNE knocked out at exon 3, region that harbors most of pathologically relevant mutations in epimerase domain. We used an AAV based SEPT technology to knock out the exon and generated a heterozygous cell line with wild type GNE allele as well as knocked out GNE allele. Though at DNA level, gene sequence was confirmed, we failed to detect RNA or protein of truncated sizes. This could be due to lack of appropriate splicing of RNA sequences or non-translation of the aberrant mRNA. The truncated RNA may have been degraded from the muscle cell. Whether the cell lines show any phenotype relevant to GNE defect, was further investigated. There was marginal reduction in total and glycoconjugate bound sialic acid of the cell, however, the epimerase activity of GNE was drastically reduced to $60 \%$ in heterozygous cell lines as compared to wild type cells. In general, the amount of functional GNE required by muscle cell is very little compared to other tissue ${ }^{55}$. Therefore, the amount of sialic acid produced by wild type allele may be sufficient for the muscle cell. However, reduction in epimerase activity of GNE may affect other cellular functions.

Previous reports from our laboratory as well as other laboratories has indicated role of GNE in regulating cell adhesion, migration, UPR pathway, ER stress and apoptosis. In particular cytoskeletal organization has been shown to be affected in muscle biopsies of GNE Myopathy patients ${ }^{20}$. Since actin plays a central role in regulating the cytoskeletal network, we addressed the effect of GNE on actin dynamics in heterozygous muscle cells. Our study indicated reduced F/G-actin ratio with drastic changes in F-actin organization. The muscle cell with knock out GNE showed disrupted actin pattern. This may have serious consequence in the muscle cell as appropriate spatial arrangement of actin is required for normal function. Alteration in actin organization could affect sarcomere organization and its association with Myosin filament thereby, affecting muscle contraction. In addition, cell migration phenomenon of the cell could be hampered which is critical for muscle cell regeneration. GNE has been shown to interact with aactinin 1 and 2, disruption in the epimerase domain may affect its ability to interact and regulate cytoskeletal organization.

In skeletal muscle, RhoA GTPase is tightly regulated during muscle differentiation. Castellani et al had shown that RhoA expression and activity were downregulated in differentiating myoblast, and increased RhoA activity inhibit muscle cell fusion ${ }^{56}$. RhoA also plays a key role in cell spreading via $\beta$-integrin signaling pathway ${ }^{57}$. Since migration of satellite cells is critical for muscle regeneration, alteration in RhoA activity can severely affect actin dynamics ${ }^{58}$. In our study, we observed an increased level of RhoA 
in SKM-GNEHz as compared to wild type L6. Increased level of RhoA in altered GNE cells might lead to inhibition of skeletal muscle differentiation which is important for muscle regeneration from satellite cells.

Cofilin also acts downstream of RhoA to regulate actin dynamics that may affect muscle cell migration and regeneration. The $\mathrm{C} 2 \mathrm{C} 12$ myoblast migration is regulated by RhoA/ROCK signaling pathway where Cofilin levels and activity is important ${ }^{59}$. Increased phosphorylation of Cofilin inhibits its actin severing activity. This affects actin dynamic pool in the cell. Continuous assembly/disassembly of actin provides driving force for cell movement ${ }^{60}$. The slow turnover rate of actin also inhibits muscle cell regeneration 61 . Inefficient actin function also causes muscle atrophy and increased loss of muscle mass. Hence, reduced F/G-actin ratios in SKM-GNEHz cell lines may contribute to altered actin dynamics and cellular pool. Disturbed actin may result in loss of muscle mass and reduced muscle regeneration observed in muscle cells with various pathologically relevant GNE mutations.

Other signaling molecules in the pathway such as Src and FAK play important role in RhoA activity. Focal Adhesion Kinase (FAK) induce down-modulation of RhoA via activation of p190RhoGAP ${ }^{62}$. Loss of FAK increased RhoA activity to limit adhesion and cellular growth ${ }^{63}$. Particularly, integrin signaling involved in cell spreading showed that both FAK and Src upregulate p190RhoGAP to inhibit RhoA activity thereby reducing stress fiber formation and actomyosin contractility ${ }^{62}$. Our study showed reduced FAK and SrC phosphorylation with increased RhoA levels in GNEHz cell lines. This indicates increased stress fibers formation and actomyosin contractility in GNE-Hz cells which may affect cell spreading and migration.

The process of myogenesis and muscle regeneration involves proliferation of satellite cells as myoblasts. The myoblast cells then migrate and align with each other for fusion to form a multinucleated myotubes or with the pre-existing muscle sarcomere ${ }^{64}$. The main player of myoblast migration are Rho GTPases which includes RhoA that modulate the actin assembly and disassembly targeting actin binding proteins like Cofilin ${ }^{65}$. Knockout of actin based motor Myosin VI in C1C12 myoblast resulted in slow myoblast migration ${ }^{66}$. The SKM-GNEHz L6 cells showed slow migration which is implicated due to slow turnover of actin. One of the main pathophysiology of GNE myopathy is atrophy. The progressive culmination of atrophy in GNE myopathy may be due to reduction in satellite cell migration thereby reducing the muscle regeneration over time.

\section{Future Perspectives}

The generated GNEHz-KO cell is a cell-based model system to understand the pathomechanism of rare neuromuscular disorder, GNE Myopathy. The cells can be used for other diseases associated with sialic acid metabolism and certain cancers. These cells can be used for drug identification for various disorders associated with glycosylation defects, in particular, sialic acid. Being a muscle cell-based model, it will particularly be useful for GNE Myopathy where hyposialylation and reduced GNE activity is demonstrated in patient muscle cells. Screening of drugs can be most efficiently studied in this model system and 
restoration of the phenotype can be followed. These cells can be used for target identification as more cellular pathways can be identified with relevance to GNE function beside sialic acid metabolism. These cells can be used for virus-host interaction studies, where virus utilize sialic acid for host cell entry.

\section{Conclusion}

In the present study, we have generated a skeletal muscle cell based model system for GNE Myopoathy with GNE knocked out at one of the allele. Though not much reduction was observed in sialic acid content, significant reduction in epimerase activity translated to its effect on other cellular functions such as cell migration. The signaling cascade regulating actin dynamics via FAK, Src, RhoA and cofilin is affected to alter actin turnover rate. Thus, GNE may play an important role in regulating cytoskeletal organization via actin dynamics. Molecules altering Rho A and Cofilin function can be further explored for therapeutic potential. The model system can be used to further understand pathomechanism underlying GNE Myopathy as it resembles skeletal muscle cell physiology.

Based on the above observations, we design a model for the role of GNE in cytoskeletal organization of muscle cell (Fig. 8). GNE interacts with a-actinin-1 and 2 to form focal adhesion complex with FAK and Src in response to integrin activation by Extracellular Matrix. This initiates downstream signaling cascade via RhoA, possibly, ROCK/LIMK that regulate Cofilin. Cofilin further regulates actin assembly and disassembly. However, when GNE is mutated or non-functional, actin binds more strongly to actinin and the activity of Src and FAK in focal adhesion complex is reduced leading to activation of RhoA, possibly via p190RhoAGAP inhibition. Upregulation of RhoA further activates LIMK and LIMK mediates phosphorylation of Cofilin. Inactive Cofilin cannot mediate F-actin severing, thereby, resulting in slow turnover of actin dynamic pool in the cell. Improper actin assembly/disassembly affects the generation of force required by cell to move forward. Hence, there is inhibition of cell migration in GNE mutant or truncated or deficient cells (Fig. 8). Different studies have proven that the migration of myoblast cell is vital for regeneration and differentiation of myoblast cell to muscle. The reduced migration of GNE deficient cells due to reduce actin turnover and actin filament might be the plausible reason for muscle degeneration in GNE myopathy.

\section{Abbreviations}

GNE: UDP-N-acetylglucosamine 2-epimerase/N-acetylmannosamine kinase; ER: endoplasmic reticulum; AAV: Adeno-associated viruses; SEPT: synthetic exon promoter trap; ERK: extracellular-signal-regulated kinase; FAK: Focal adhesion kinase; Src: Proto-oncogene tyrosine-protein kinase (sarcoma); ManNac: NAcetylmannosamine; NCAM: Neural cell adhesion molecule; UPR: Unfolded protein response; CRMP1: Collapsin response mediator protein 1; ROCK: Rho-associated protein kinase; LIMK: LIM (Lin-11 Isl-1 Mec-

3) Kinase; $A \beta$ 1-42: Amyloid- $\beta$ 1-42; loxP: locus of X-over P1.

\section{Declarations}


Acknowledgement: We acknowledge Prof. Sudha Bhattacharya, School of Environmental Sciences, Jawaharlal Nehru University, India and Prof. Alok Bhattacharya, Ashoka University for their support and help during the project. We also acknowledgeDr. Sivaprakash Ramalingam, IGIB for valuable suggestions. We acknowledge Advanced Instrumentation Research facility, JNU and its staff members (Ashok Sahu, and Prabhat Yadav) for helping in acquiring confocal images.

Authors Contribution: RA conceptualized, designed, brought financial support through grants and analyzed the data. RA compiled and wrote the manuscript. SSD performed the experiments, generated the cell line and characterized the cell line and helped in manuscript draft writing. RY validated the data by performing experiments, blind study and editing of the manuscript. FM confirmed the cell lines through sequencing and performed sialic acid content study. PC characterized the cell line by performing epimerase assay and helped in literature search. SS performed kinase assay and helped in editing of the manuscript. All authors read and approved the final manuscript.

Funding: This work was funded by Science and Engineering Research Board, Department of Science and Technology, India, Department of Biotechnology, India and Department of Atomic Energy, Board of Research in Nuclear Sciences (BRNS), India.

Ethics Approval and consent to participate:The study was performed in the laboratory cell lines and does not involve human or animal subjects.

Consent for publication: All the authors have given consent for publication

Competing Interest: The authors declare no competing interest.

Availability of data and material: All the data is enclosed in the manuscript and supplementary materials. Anything else required shall be provided.

Author's Information: ${ }^{1}$ School of Biotechnology, Jawaharlal Nehru University, New Delhi, India-110067

\section{References}

1. Awasthi K, Arya R, Bhattacharya A, Bhattacharya S. The Inherited Neuromuscular Disorder GNE Myopathy: Research to Patient Care. Neurol India. 2019. doi:10.4103/0028-3886.271259.

2. Carrillo N, Malicdan MC, Huizing MGNE, Myopathy. Etiology, Diagnosis, and Therapeutic Challenges. Neurotherapeutics. 2018;15(4):900-14. doi:10.1007/s13311-018-0671-y.

3. Benyamini H, Kling Y, Yakovlev L, et al. Upregulation of Hallmark Muscle Genes Protects GneM743T/M743T Mutated Knock-In Mice from Kidney and Muscle Phenotype. J Neuromuscul Dis. 2020. doi:10.3233/JND-190461.

4. Pogoryelova O, Wilson IJ, Mansbach H, Argov Z, Nishino I, Lochmüller H. GNE genotype explains $20 \%$ of phenotypic variability in GNE myopathy. Neurol Genet. 2019;5(1).

doi:10.1212/NXG.0000000000000308.

Page 17/31 
5. Celeste FV, Vilboux T, Ciccone C, et al. Mutation Update for GNE Gene Variants Associated with GNE Myopathy. Hum Mutat. 2014;35(8):915-26. doi:10.1002/humu.22583.

6. Chakravorty S, Berger $\mathrm{K}$, Arafat $\mathrm{D}$, et al. Clinical utility of RNA sequencing to resolve unusual GNE myopathy with a novel promoter deletion. Muscle and Nerve. 2019:1-6. doi:10.1002/mus.26486.

7. Park YE, Kim DS, Choi YC, Shin JH. Progression of GNE myopathy based on the patient-reported outcome. J Clin Neurol. 2019. doi:10.3988/jcn.2019.15.3.275.

8. Yonekawa T, Malicdan MCV, Cho A, et al. Sialyllactose ameliorates myopathic phenotypes in symptomatic GNE myopathy model mice. Brain. 2014;137(10):2670-9. doi:10.1093/brain/awu210.

9. Argov Z, Caraco Y, Lau H, et al. Aceneuramic Acid Extended Release Administration Maintains Upper Limb Muscle Strength in a 48-week Study of Subjects with GNE Myopathy: Results from a Phase 2, Randomized, Controlled Study. J Neuromuscul Dis. 2016. doi:10.3233/JND-159900.

10. Lochmüller $\mathrm{H}$, Behin A, Caraco $\mathrm{Y}$, et al. A phase 3 randomized study evaluating sialic acid extendedrelease for GNE myopathy. Neurology. 2019;92(18):e2109-17. doi:10.1212/WNL.0000000000006932.

11. Pogoryelova O, González Coraspe JA, Nikolenko N, Lochmüller H, Roos A. GNE myopathy: From clinics and genetics to pathology and research strategies. Orphanet J Rare Dis. 2018;13(1):1-15. doi:10.1186/s13023-018-0802-x.

12. Nishino I, Carrillo-Carrasco N, Argov Z. GNE myopathy: Current update and future therapy. J Neurol Neurosurg Psychiatry. 2015;86(4):385-92. doi:10.1136/jnnp-2013-307051.

13. Valles-Ayoub Y, Esfandiarifard S, Sinai P, et al. Serum Neural Cell Adhesion Molecule Is Hyposialylated in Hereditary Inclusion Body Myopathy. Genet Test Mol Biomarkers. 2012;16(5):3137. doi:10.1089/gtmb.2011.0146.

14. Grover S, Arya R. Role of UDP-N-Acetylglucosamine2-Epimerase/N-Acetylmannosamine Kinase (GNE) in ??1-Integrin-Mediated Cell Adhesion. Mol Neurobiol. 2014;50(2):257-73. doi:10.1007/s12035-013-8604-6.

15. Eisenberg I, Avidan N, Potikha T, et al. The UDP-N-acetylglucosamine 2-epimerase/Nacetylmannosamine kinase gene is mutated in recessive hereditary inclusion body myopathy. Nat Genet. 2001;29(1):83-7. doi:10.1038/ng718.

16. Grover S, Arya R. Role of UDP-N-Acetylglucosamine2-Epimerase/N-Acetylmannosamine Kinase (GNE) in $\beta 1$-Integrin-Mediated Cell Adhesion. Mol Neurobiol. 2014;50(2):257-73. doi:10.1007/s12035-013-8604-6.

17. Chanana P, Padhy G, Bhargava K, Arya R. Mutation in GNE Downregulates Peroxiredoxin IV Altering ER Redox Homeostasis. NeuroMolecular Med. 2017;19(4):525-40. doi:10.1007/s12017-017-8467-5.

18. Sela I, Yakovlev L, Becker Cohen M, et al. Variable phenotypes of knockin mice carrying the M712T Gne mutation. NeuroMolecular Med. 2013. doi:10.1007/s12017-012-8209-7.

19. Li H, Chen Q, Liu F, et al. Unfolded Protein Response and Activated Degradative Pathways Regulation in GNE Myopathy. PLoS One. 2013;8(3):1-9. doi:10.1371/journal.pone.0058116. 
20. Sela I, Krentsis IM, Shlomai Z, et al. The proteomic profile of hereditary inclusion body myopathy. PLoS One. 2011;6(1). doi:10.1371/journal.pone.0016334.

21. Weidemann W, Stelzl U, Lisewski U, et al. The collapsin response mediator protein 1 (CRMP-1) and the promyelocytic leukemia zinc finger protein (PLZF) bind to UDP-N-acetylglucosamine 2epimerase/N-acetylmannosamine kinase (GNE), the key enzyme of sialic acid biosynthesis. FEBS Lett. 2006;580(28-29):6649-54. doi:10.1016/j.febslet.2006.11.015.

22. Amsili S, Zer H, Hinderlich S, et al. UDP-N-acetylglucosamine-2-epimerase/N-acetylmannosamine kinase (GNE) binds to alpha-actinin 1: Novel pathways in skeletal muscle? PLoS One. 2008;3(6). doi:10.1371/journal.pone.0002477.

23. Harazi A, Becker-Cohen M, Zer H, Moshel O, Hinderlich S, Mitrani-Rosenbaum S. The Interaction of UDP-N-Acetylglucosamine 2-Epimerase/N-Acetylmannosamine Kinase (GNE) and Alpha-Actinin 2 Is Altered in GNE Myopathy M743T Mutant. Mol Neurobiol. 2017;54(4):2928-38. doi:10.1007/s12035016-9862-x.

24. Henderson CA, Gomez CG, Novak SM, Mi-Mi L, Gregorio CC. Overview of the muscle cytoskeleton. Compr Physiol. 2017. doi:10.1002/cphy.c160033.

25. Kowalski K, Kołodziejczyk A, Sikorska M, et al. Stem cells migration during skeletal muscle regeneration - the role of Sdf-1/Cxcr4 and Sdf-1/Cxcr7 axis. Cell Adhes Migr. 2017. doi:10.1080/19336918.2016.1227911.

26. Fan J, Chan C, McNamara EL, Nowak KJ, Iwamoto H, Ochala J. Molecular Consequences of the Myopathy-Related D286G Mutation on Actin Function. Front Physiol. 2018. doi:10.3389/fphys.2018.01756.

27. Horak I, Rohde E, Wiechens $\mathrm{N}$, et al. Sialylation is essential for early development in mice. Proc Natl Acad Sci. 2002. doi:10.1073/pnas.072066199.

28. Galeano B, Klootwijk R, Manoli I, et al. Mutation in the key enzyme of sialic acid biosynthesis causes severe glomerular proteinuria and is rescued by $\mathrm{N}$-acetylmannosamine. J Clin Invest. 2007;117(6):1585-94. doi:10.1172/JCl30954.

29. Schwarzkopf M, Knobeloch K-P, Rohde E, et al. Sialylation is essential for early development in mice. Proc Natl Acad Sci U S A. 2002;99(8):5267-70. doi:10.1073/pnas.072066199.

30. Malicdan MCV, Noguchi S, Nishino I. Autophagy in a mouse model of distal myopathy with rimmed vacuoles or hereditary inclusion body myopathy. Autophagy. 2007;3(4):396-8. doi:10.4161/auto.4270.

31. Daya A, Vatine GD, Becker-Cohen M, et al. Gne depletion during zebrafish development impairs skeletal muscle structure and function. Hum Mol Genet. 2014. doi:10.1093/hmg/ddu045.

32. Bosch-Morató M, Iriondo C, Guivernau B, et al. Increased amyloid $\beta$-peptide uptake in skeletal muscle is induced by hyposialylation and may account for apoptosis in GNE myopathy. Oncotarget. 2016;7(12):13354-71. doi:10.18632/oncotarget.7997.

33. Tanner ME. The enzymes of sialic acid biosynthesis. Bioorg Chem. 2005. doi:10.1016/j.bioorg.2005.01.005. 
34. Yuan Z, Qiao C, Hu P, Li J, Xiao X. A versatile adeno-associated virus vector producer cell line method for scalable vector production of different serotypes. Hum Gene Ther. 2011. doi:10.1089/hum.2010.241.

35. Bork K, Reutter W, Weidemann W, Horstkorte R. Enhanced sialylation of EPO by overexpression of UDP-GIcNAc 2-epimerase/ManAc kinase containing a sialuria mutation in $\mathrm{CHO}$ cells. FEBS Lett. 2007. doi:10.1016/j.febslet.2007.07.060.

36. Blume A, Ghaderi D, Liebich V, et al. UDP-N-acetylglucosamine2-epimerase/N-acetylmannosamine kinase, functionally expressed in and purified from Escherichia coli, yeast, and insect cells. Protein Expr Purif. 2004;35(2):387-96. doi:10.1016/j.pep.2004.02.013.

37. Reissig JL, Strominger JL, Leloir LF. A modified estimation. J Biol Chem. 1955:959-966.

38. Rago C, Vogelstein B, Bunz F. Genetic knockouts and knockins in human somatic cells. Nat Protoc. 2007. doi:10.1038/nprot.2007.408.

39. Van Helvert S, Storm C, Friedl P. Mechanoreciprocity in cell migration. Nat Cell Biol. 2018. doi:10.1038/s41556-017-0012-0.

40. DesMarais V, Ghosh M, Eddy R, Condeelis J. Cofilin takes the lead. J Cell Sci. 2004. doi:10.1242/jcs.01631.

41. Suetsugu S, Takenawa T. Regulation of cortical actin networks in cell migration. Int Rev Cytol. 2003. doi:10.1016/S0074-7696(03)29006-9.

42. Ono S. Dynamic regulation of sarcomeric actin filaments in striated muscle. Cytoskeleton. 2010. doi:10.1002/cm.20476.

43. Sampath SC, Sampath SC, Millay DP. Myoblast fusion confusion: The resolution begins. Skelet Muscle. 2018. doi:10.1186/s13395-017-0149-3.

44. Webster MT, Fan CM. c-MET regulates myoblast motility and myocyte fusion during adult skeletal muscle regeneration. PLoS One. 2013. doi:10.1371/journal.pone.0081757.

45. Nobes CD, Hall A. Rho GTPases control polarity, protrusion, and adhesion during cell movement. J Cell Biol. 1999. doi:10.1083/jcb.144.6.1235.

46. Mu X, Usas A, Tang Y, et al. RhoA mediates defective stem cell function and heterotopic ossification in dystrophic muscle of mice. FASEB J. 2013. doi:10.1096/fj.13-233460.

47. Costa P, Scales TME, Ivaska J, Parsons M. Integrin-Specific Control of Focal Adhesion Kinase and RhoA Regulates Membrane Protrusion and Invasion. PLoS One. 2013;8(9). doi:10.1371/journal.pone.0074659.

48. Katoh K, Kano Y, Noda Y. Rho-associated kinase-dependent contraction of stress fibres and the organization of focal adhesions. J R Soc Interface. 2011. doi:10.1098/rsif.2010.0419.

49. Destaing $O$, Sanjay A, Itzstein $C$, et al. The tyrosine kinase activity of c-Src regulates actin dynamics and organization of podosomes in osteoclasts. Mol Biol Cell. 2008. doi:10.1091/mbc.E07-03-0227.

50. Graham ZA, Gallagher PM, Cardozo CP. Focal adhesion kinase and its role in skeletal muscle. J Muscle Res Cell Motil. 2015. doi:10.1007/s10974-015-9415-3. 
51. Li SY, Mruk DD, Cheng CY. Focal adhesion kinase is a regulator of F-actin dynamics. Spermatogenesis. 2013. doi:10.4161/spmg.25385.

52. Tsai WC, Yu TY, Lin LP, Lin MS, Tsai TT, Pang JHS. Platelet rich plasma promotes skeletal muscle cell migration in association with up-regulation of FAK, paxillin, and F-Actin formation. J Orthop Res. 2017. doi:10.1002/jor.23547.

53. Pollard TD, Cooper JA. Actin, a central player in cell shape and movement. Science (80-). 2009. doi:10.1126/science.1175862.

54. Tang DD, Gerlach BD. The roles and regulation of the actin cytoskeleton, intermediate filaments and microtubules in smooth muscle cell migration. Respir Res. 2017. doi:10.1186/s12931-017-0544-7.

55. Jank T, Eckerle S, Steinemann M, et al. Tyrosine glycosylation of Rho by Yersinia toxin impairs blastomere cell behaviour in zebrafish embryos. Nat Commun. 2015. doi:10.1038/ncomms8807.

56. Castellani L, Salvati E, Alemà S, Falcone G. Fine regulation of RhoA and Rock is required for skeletal muscle differentiation. J Biol Chem. 2006. doi:10.1074/jbc.M601390200.

57. Huveneers S, Danen EHJ. Adhesion signaling - crosstalk between integrins, Src and Rho. J Cell Sci. 2009. doi:10.1242/jcs.039446.

58. Urciuolo A, Urbani L, Perin S, et al. Decellularised skeletal muscles allow functional muscle regeneration by promoting host cell migration. Sci Rep. 2018. doi:10.1038/s41598-018-26371-y.

59. Wang W, Chen M, Gao Y, et al. P2Y6 regulates cytoskeleton reorganization and cell migration of C2C12 myoblasts via ROCK pathway. J Cell Biochem. 2018. doi:10.1002/jcb.26350.

60. Ridley AJ. Life at the leading edge. Cell. 2011;145(7):1012-22. doi:10.1016/j.cell.2011.06.010.

61. Ambriz X, De Lanerolle P, Ambrosio JR. The mechanobiology of the actin cytoskeleton in stem cells during differentiation and interaction with biomaterials. Stem Cells Int. 2018. doi:10.1155/2018/2891957.

62. Holinstat M, Knezevic N, Broman M, Samarel AM, Malik AB, Mehta D. Suppression of RhoA activity by focal adhesion kinase-induced activation of p190RhoGAP: Role in regulation of endothelial permeability. J Biol Chem. 2006. doi:10.1074/jbc.M511248200.

63. Pirone DM, Liu WF, Ruiz SA, et al. An inhibitory role for FAK in regulating proliferation: A link between limited adhesion and RhoA-ROCK signaling. J Cell Biol. 2006. doi:10.1083/jcb.200510062.

64. Lehka L, Rędowicz MJ. Mechanisms regulating myoblast fusion: A multilevel interplay. Semin Cell Dev Biol. 2020. doi:10.1016/j.semcdb.2020.02.004.

65. Blanchoin L, Boujemaa-Paterski R, Sykes C, Plastino J. Actin dynamics, architecture, and mechanics in cell motility. Physiol Rev. 2014. doi:10.1152/physrev.00018.2013.

66. Karolczak J, Pavlyk I, Majewski Ł, et al. Involvement of unconventional myosin VI in myoblast function and myotube formation. Histochem Cell Biol. 2015. doi:10.1007/s00418-015-1322-6.

\section{Figures}




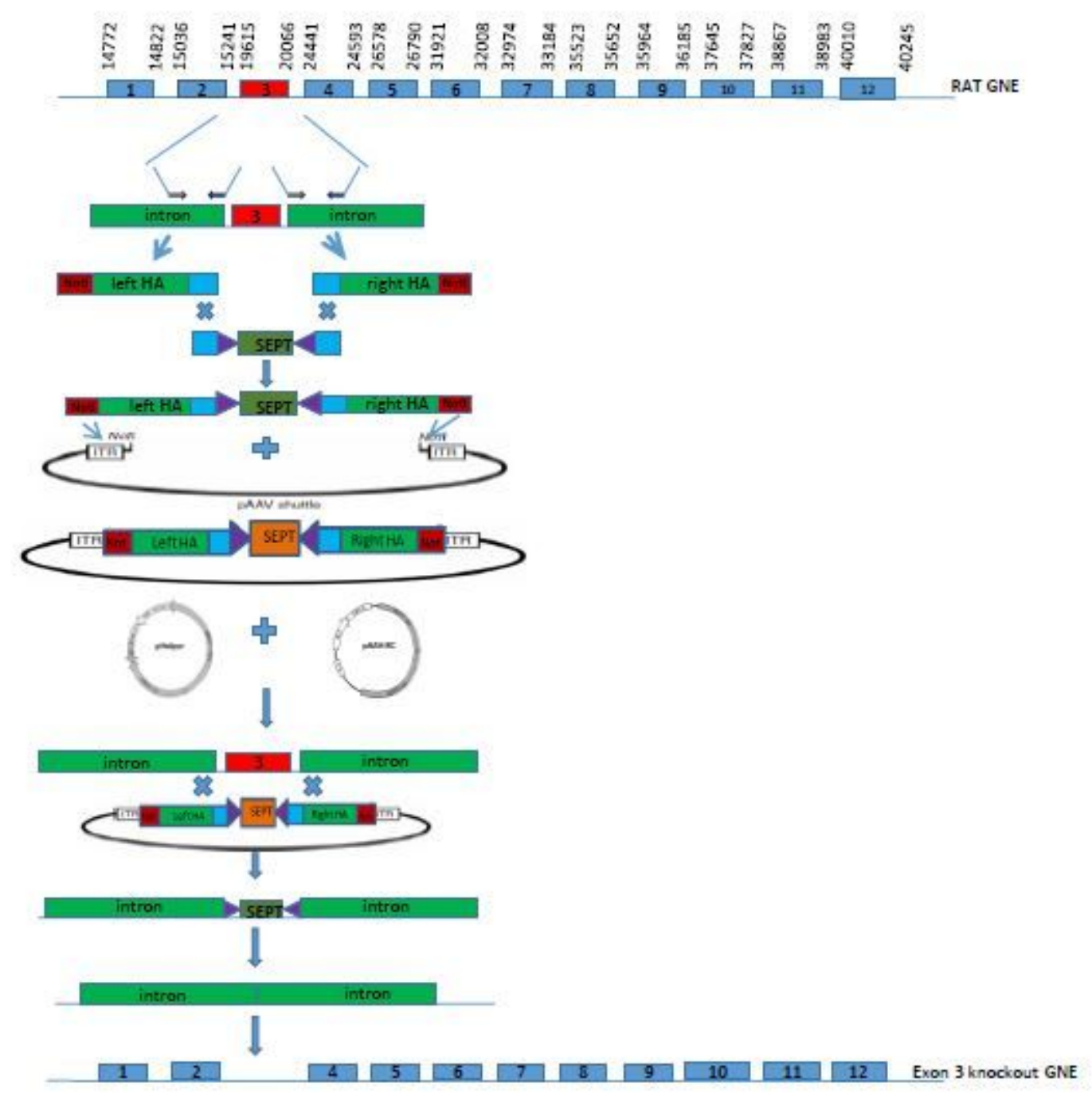

Figure 1

Strategy for the generation of GNE exon-3 knockout in L6 cells. Homology arms were amplified from the intronic regions upstream and downstream of exon 3. SEPT fragment containing Neo- gene was ligated in the pAAV-MCS vector flanked by left and right homology arms for the generation of shuttle vector. AAVviral stock was generated by infecting AAV-293 cell with shuttle vector, RC vector and Helper vector. The virus was used to infect L6 cell line and SEPT positive clones were selected using neocin drug. The positive clone was viral infected with Ad-Cre virus that harbor Cre-recombinase gene and the SEPT gene was excised at loxPsite. Infected clones were cultured in replica with one plate treating with Neomycin drug and the other replica without drug. Positive clones were neomycin sensitive clones and selected from the neomycin negative plate. 
a

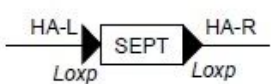

b

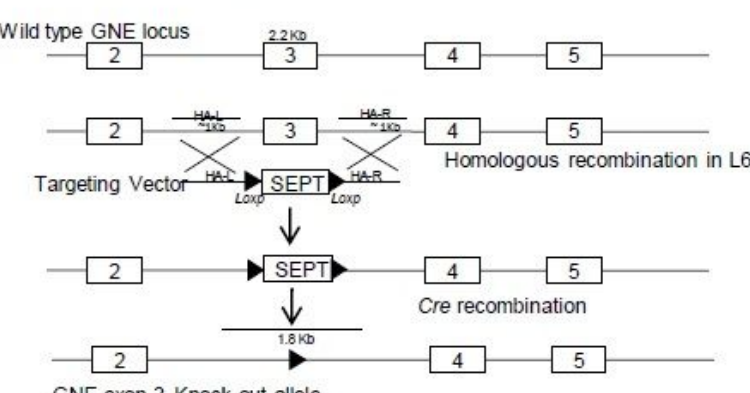

GNE exon-3 Knock out allele

c

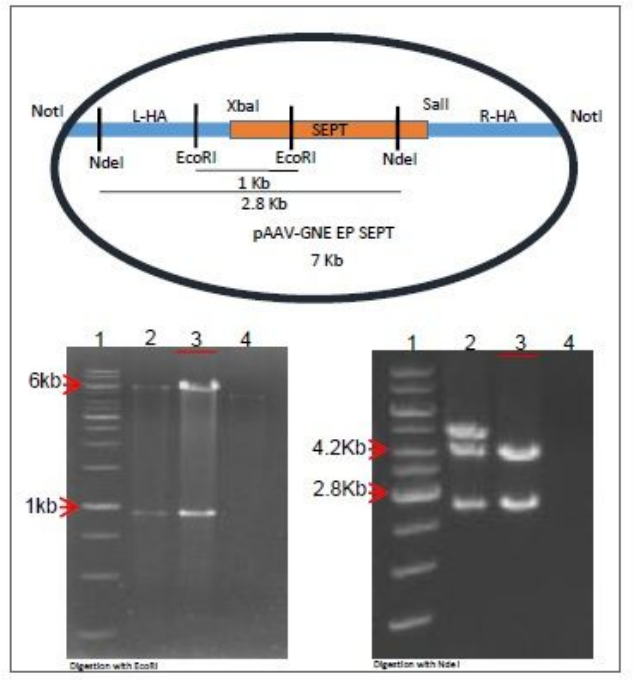

d

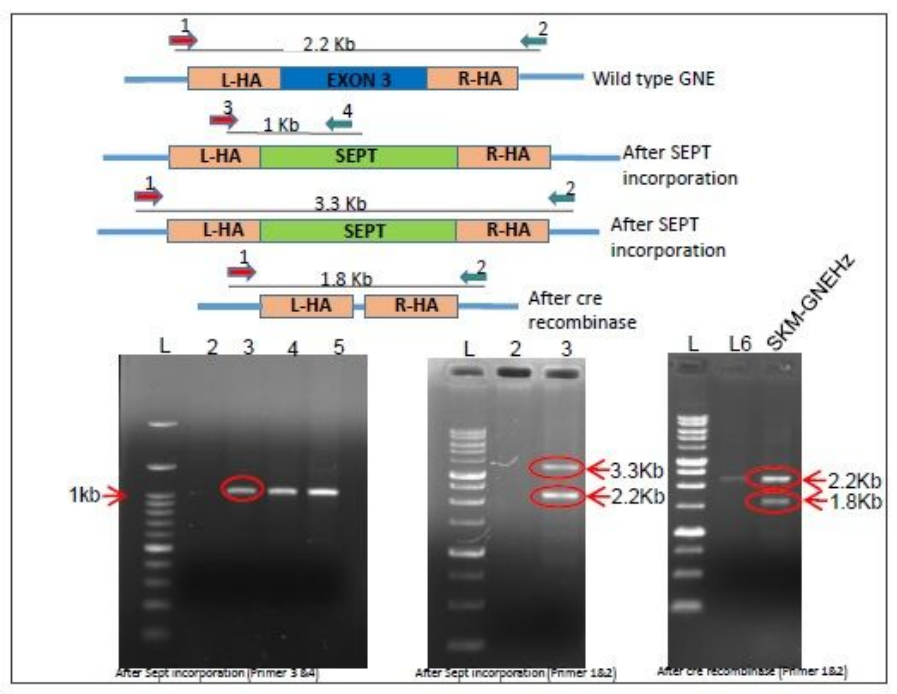

Figure 2

2a; Generation of Exon 3 knockout in L6 rat skeletal muscle cell. A: Schematic of SEPT construct. SEPT, Synthetic Exon Promoter Trap, consist of neo gene flank by loxPsites that allow excision of SEPT with Cre recombination. The SEPT does not have promoter of its own and utilizes the promoter of the target gene that minimizes the off-target clone selection. $2 b$; Schematic diagram for homology recombination for the generation of GNE exon 3 knockout. Homology arms were cloned from intronic region upstream and 
downstream of exon 3. The targeting vector is the shuttle vector that harbor the SEPT flank by homology arms in left and right of the SEPT. After successful homology recombination at the homology arms, the SEPT construct replaces the exon 3. Further, the SEPT construct is removed from the GNE genome by Crerecombinase leaving the GNE gene without exon 3 sequence. 2c; Screening of pAAV shuttle vector, cloned in pAAV-MCS vector using restriction mapping. Above figure shows the restriction mapping of shuttle vector using EcoRI and Ndel. Restriction digestion of shuttle vector generates two fragments, $1 \mathrm{~Kb}$ and 6 $\mathrm{Kb}$ while the restriction digestion of shuttle vector generates two fragments of $2.8 \mathrm{~Kb}$ and $4.2 \mathrm{~Kb}$. Below left; 3 clones were selected after ligation of homology arms and SEPT with pAAV-MCS vector. Plasmid DNA of the three clones were digested with EcoRI restriction enzyme and the sample were run in $1 \%$ agarose gel. Below right; the three clones selected and plasmid DNA of the clones were digested with Ndel restriction enzyme and the sample were run in 1\% agarose gel. 2d; Above; Amplicon size using different primers. Below left; L6 cells were infected with AAV-virus harboring shuttle vector for exon 3 and single clones were grown in 96 well plate in presence of $800 \mu \mathrm{g} / \mathrm{ml} \mathrm{G} 418$ drug (Invivogen). Genomic DNA were isolated and used for PCR screening for successful incorporation of SEPT in the GNE gene.

Genomic DNA were used as template for PCR amplification with primers 3 and 4 . The amplified sample were loaded in 1\% agarose gel. $L$ represents ladder, 2 represents $L 6,3,4$ and 5 represent clone 1,2 and 3. Below middle; PCR amplification was conducted with primer 1 and 2 and loaded in $1 \%$ agarose gel. Below right; SEPT incorporated cell was infected with Ad-Cre virus and SEPT was excised at loxPsite by Cre-recombinase. Genomic DNA was isolated from the positive clone and used for PCR screening using Primer 1 and 2. L represents ladder. 
a

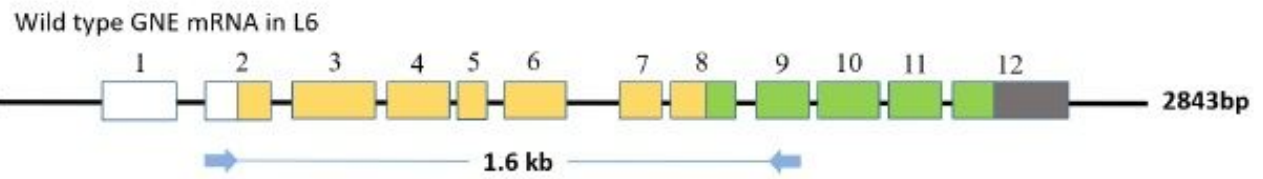

\section{Exon 3 knocked out GNE mRNA in L6}

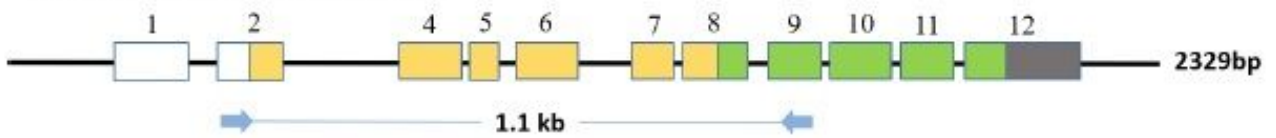

b
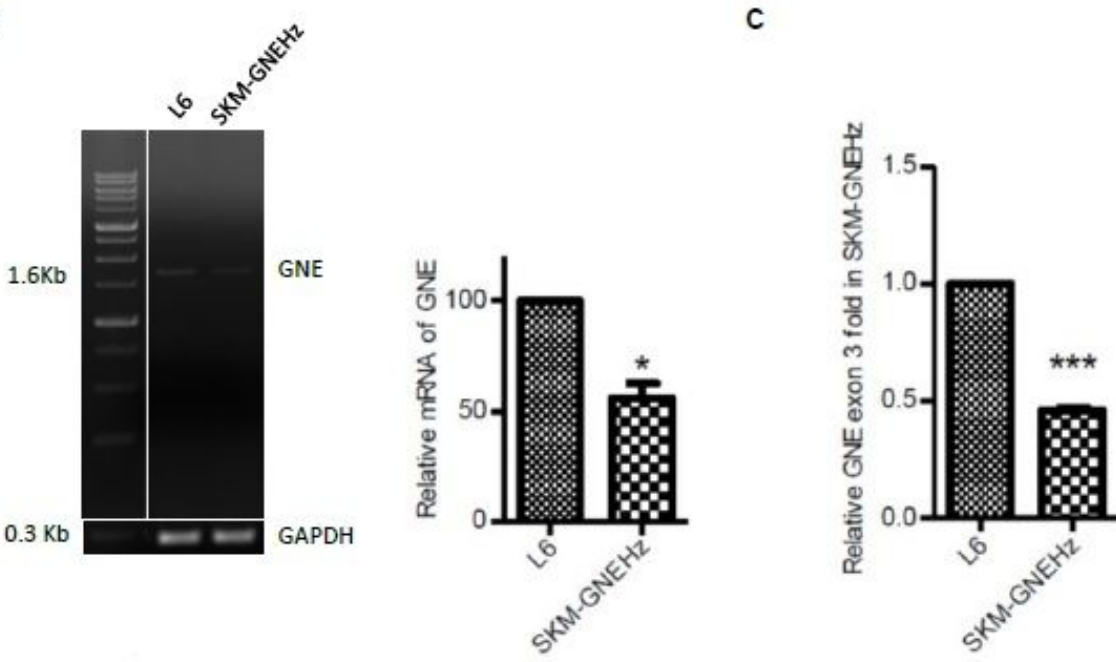

d

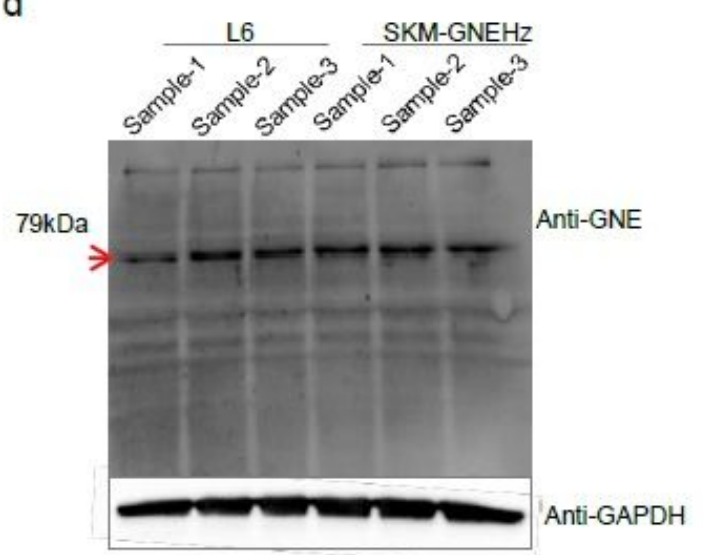

\section{Figure 3}

Characterization of GNE Exon-3 konckout cell line. 3a; Schematic diagram of mRNA construct of GNE in Rat. Above; wild type rat GNE has 12 exons with 2883bp. Primers was designed (5 and 6 ) spanning from exon 2 to exon 8 with an amplicon size of $1.6 \mathrm{~Kb}$. Below; After exon 3 knockout the mRNA of SKM-GNEHz with 2329 bp detecting a $1.1 \mathrm{~Kb}$ in PCR with primer 5 and 6 . 3b; Cells were grown in 6 well plates and mRNA were isolate using one step RNA isolation reagent followed by cDNA synthesis with random 
hexamers. RT-PCR was conducted using primer 5 and 6 followed by loading the sample in $1 \%$ agarose gel. Graph shows the densitometry analysis of the band normalized with GAPDH using ImageJ.Statistical analysis was assessed using t-test and p-value for * is 0.0228. 3c; Cells were grown in DMEM and genomic DNA was isolated using QIAGEN DNA kit. Quantitative PCR was set with SYBR green using 50 ng of genomic DNA with primer specific to exon 3. The CT value was analysed and normalized with CT value for quantitative PCR with primer specific to exon 1. 3d; Cells were grown in DCCM media for $24 \mathrm{~h}$ followed by lysis with RIPA buffer. $100 \mu \mathrm{g}$ of protein lysate were loaded on SDS-PAGE followed by Western transfer. The sample was immunoblotted with anti-GNE antibody.

a

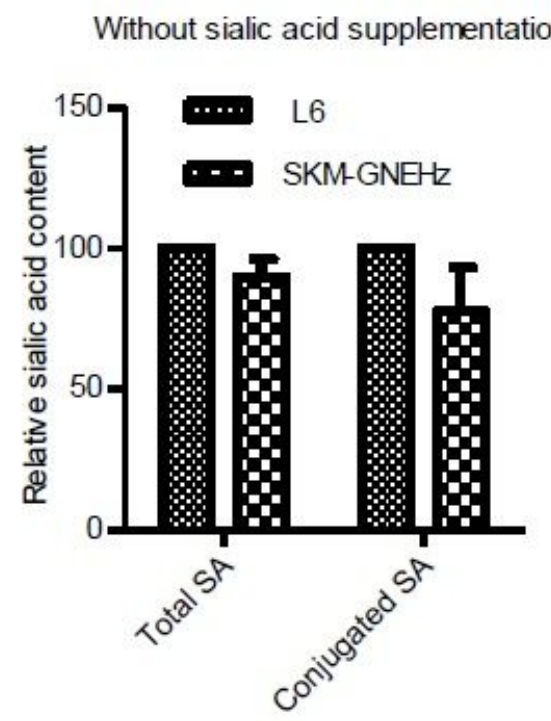

b

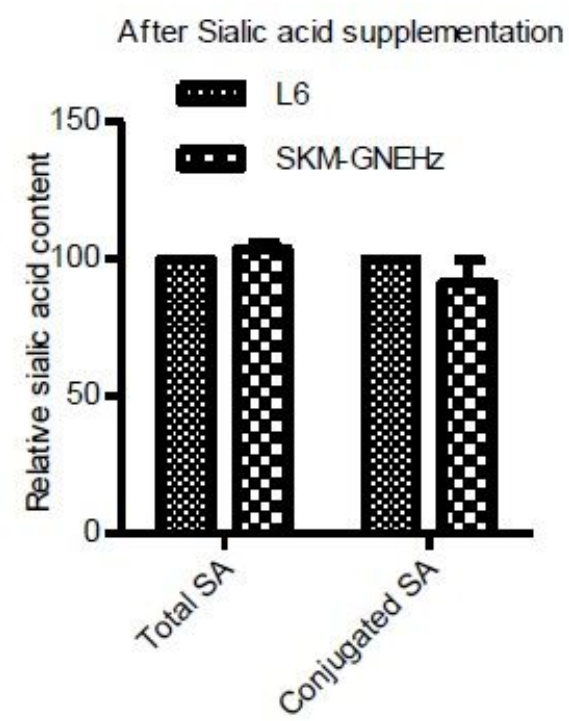

C

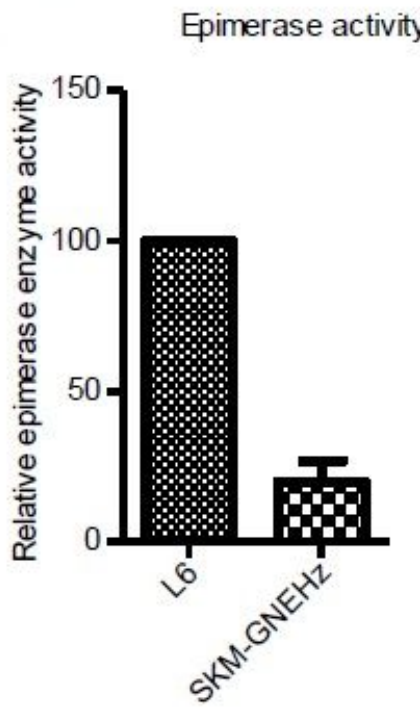

Figure 4

Characterization of SKM-GNEHz L6 cells. 4a; Sialic acid contents of SKM-GNEHz determined using Periodic acid and resorcinol methods in cell without sialic acid supplementation. 4b; Sialic acid contents of SKM-GNEHz with sialic acid supplementation. 4c; Epimerase enzyme activity of GNE in SKM-GNEHz as compared to wildtype L6. 
a

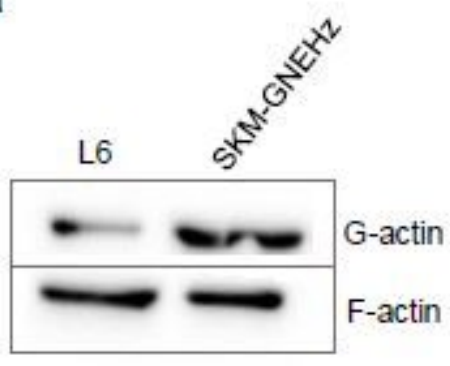

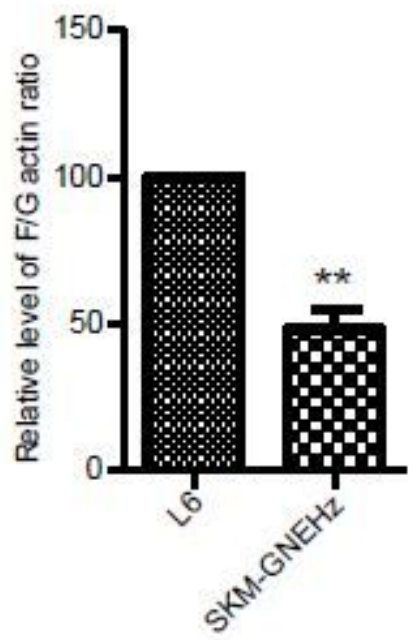

b

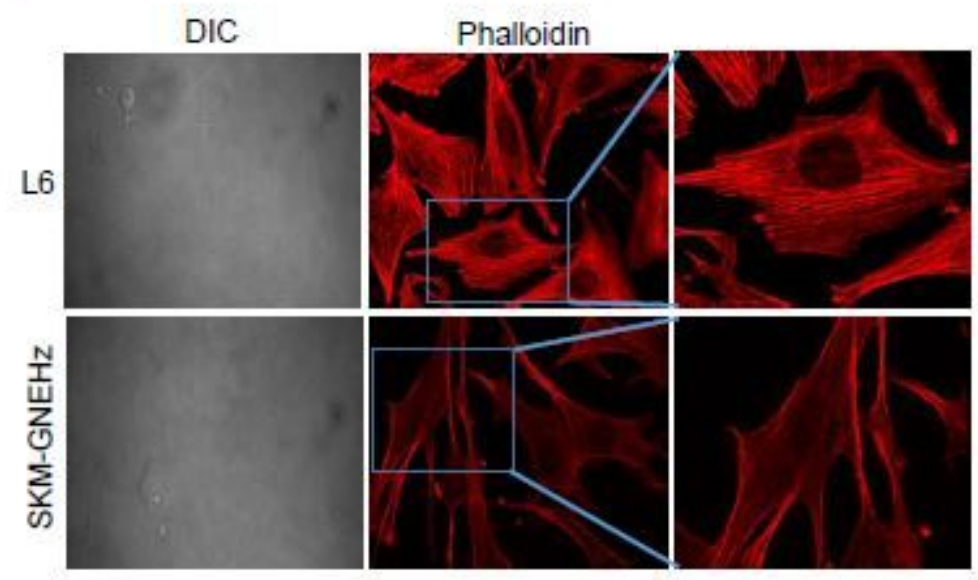

\section{Figure 5}

Effect of GNE exon-3 knockout on actin dynamic in rat skeletal muscle cell. 5a; Cells were grown in DCCM media for $24 \mathrm{~h}$ followed by isolation of $\mathrm{G}$ and $\mathrm{F}$ fraction with PIPES buffer and cytochalasin $\mathrm{D}$ as mentioned in materials \& methods. F and $\mathrm{G}$ actin fractions were loaded on SDS-PAGE followed by western blotting and immunoblotting with anti-actin antibody. F/G actin ratio was analyzed and statistical analysis was assessed with t-test and p-value for $* \star$ is 0.0039 . 5 b; Cells were grown in DCCM media for $24 \mathrm{~h}$ and fixed the cells with 3.7\% paraformaldehyde. The fixed cells were stained with TRITCphalloidin for $30 \mathrm{~min}$ and mounted on slides. Images were captured in Olympus FluoView confocal microscope with $60 \mathrm{X}$ magnification. 
a
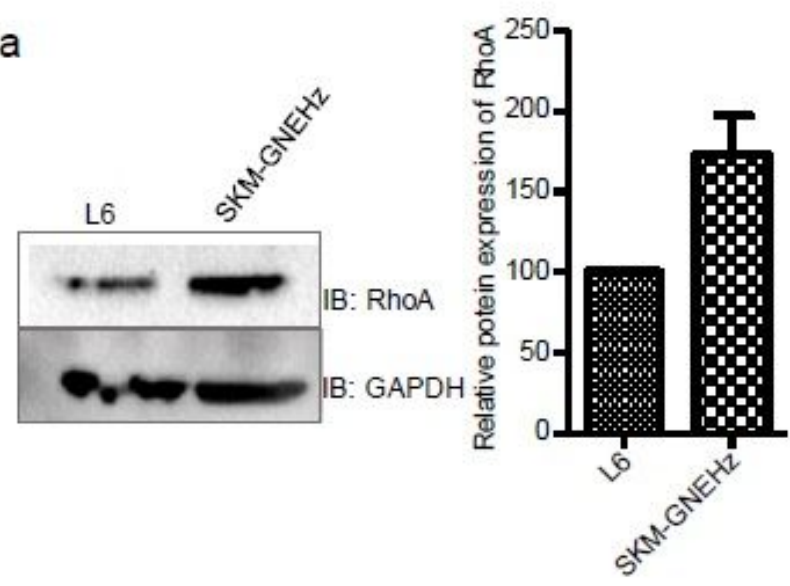

C

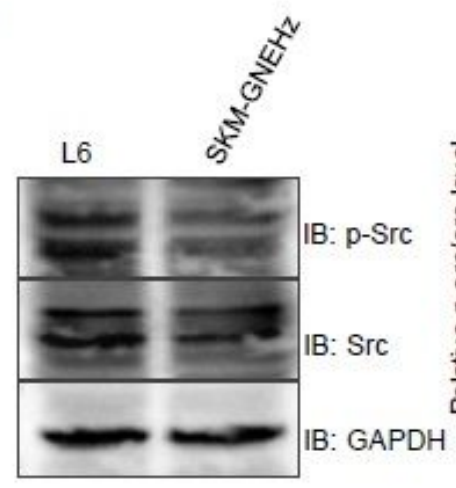

b

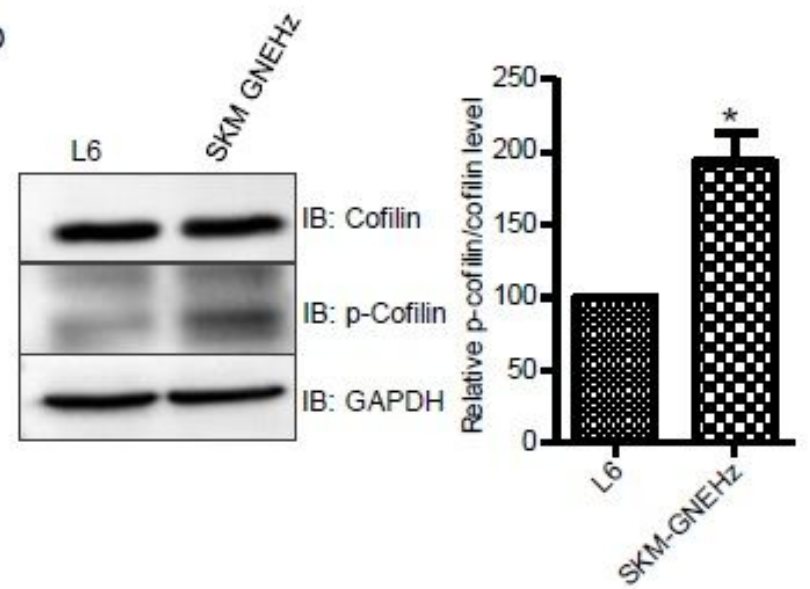

d

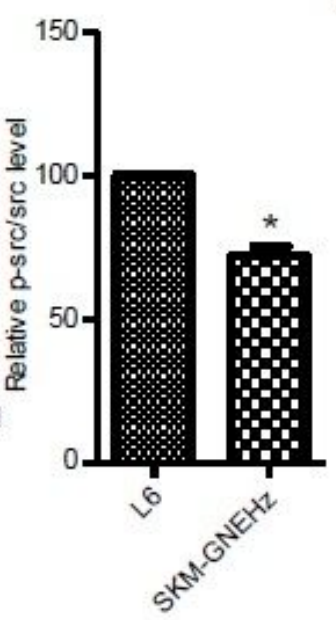

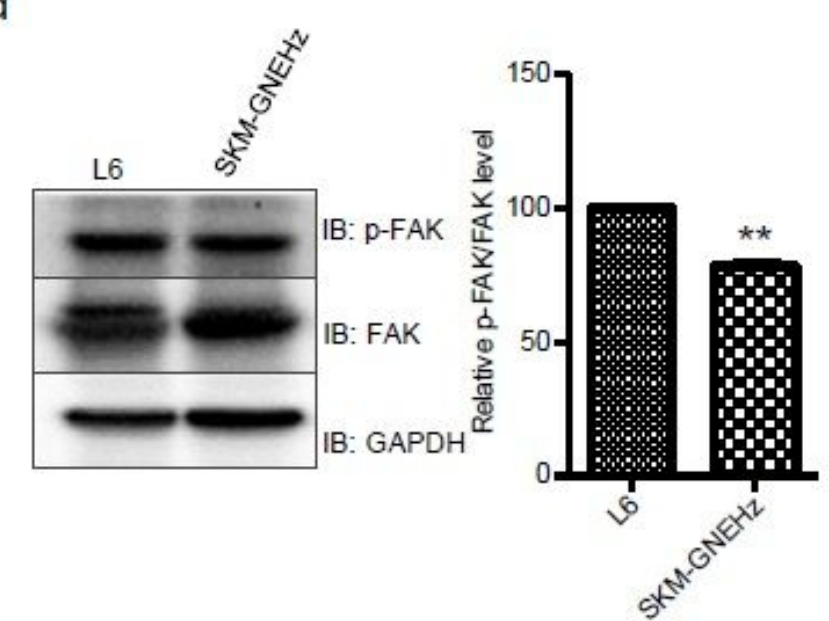

Figure 6

GNE exon 3 knockout affects RhoA signaling and its effector molecule. 6a; Cells were grown in DCCM media for $24 \mathrm{~h}$ and lysed with RIPA buffer and protein lysate was loaded on SDS-PAGE. Western transfer was done and immunoblotting was conducted with anti-RhoA antibody. 6b; Protein expression level of total Cofilin and phospho-Cofilin. Statistical analysis was assessed with t-test and p-value of * is 0.024 . 6c; Protein expression level of total Src and phospho-Src. Statistical analysis was assessed with t-test and p-value of * is 0.017. D; Protein expression level of total FAK and phospho-FAK. Statistical analysis was assessed with t-test and p-value of $* *$ is 0.0049 . 

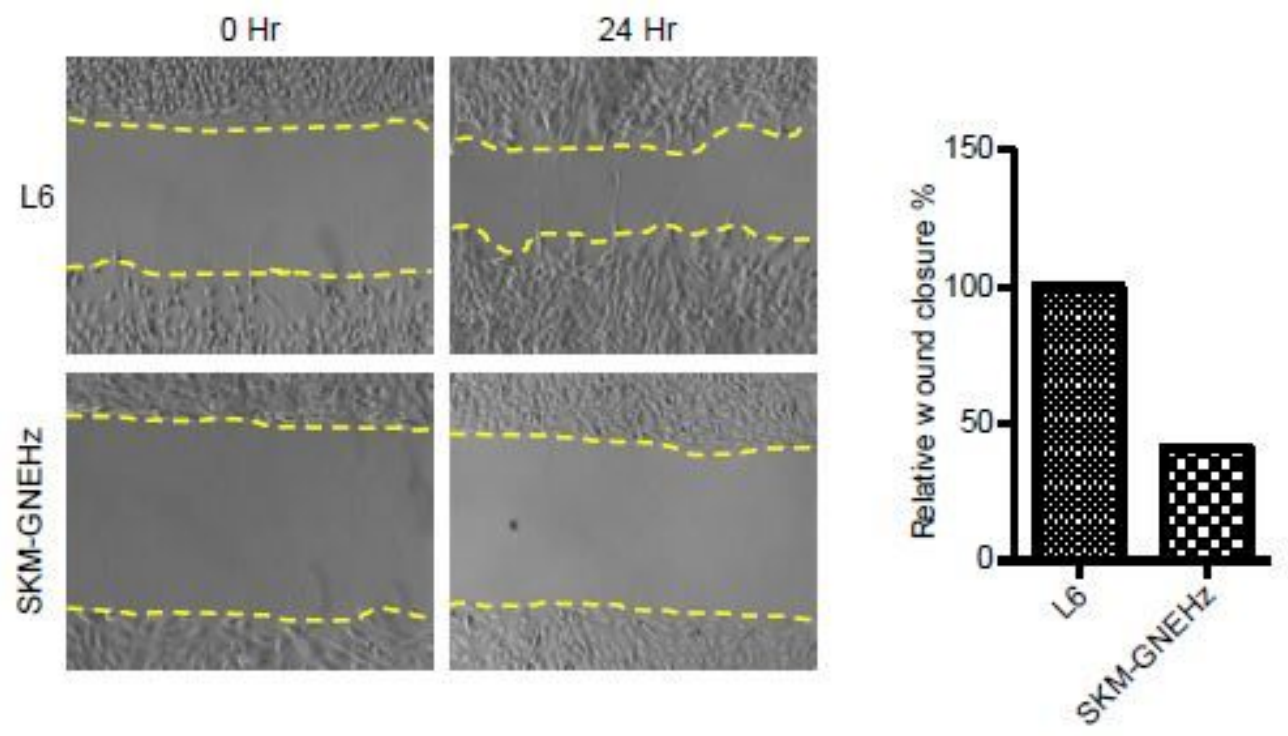

Figure 7

Effect of GNE exon 3 knockout in L6 myoblast cell migration. SKM-GNEHz cells were grown in DCCM media for $24 \mathrm{~h}$ inside IBIDI cell culture insert. Wound was created by removing the cell culture insert and images were captured at $20 \mathrm{X}$ magnification at $0 \mathrm{~h}$ and $24 \mathrm{~h}$ in an inverted microscope. Wound closure percentage was calculated from the area uncovered by the cells determined through ImageJ software. 


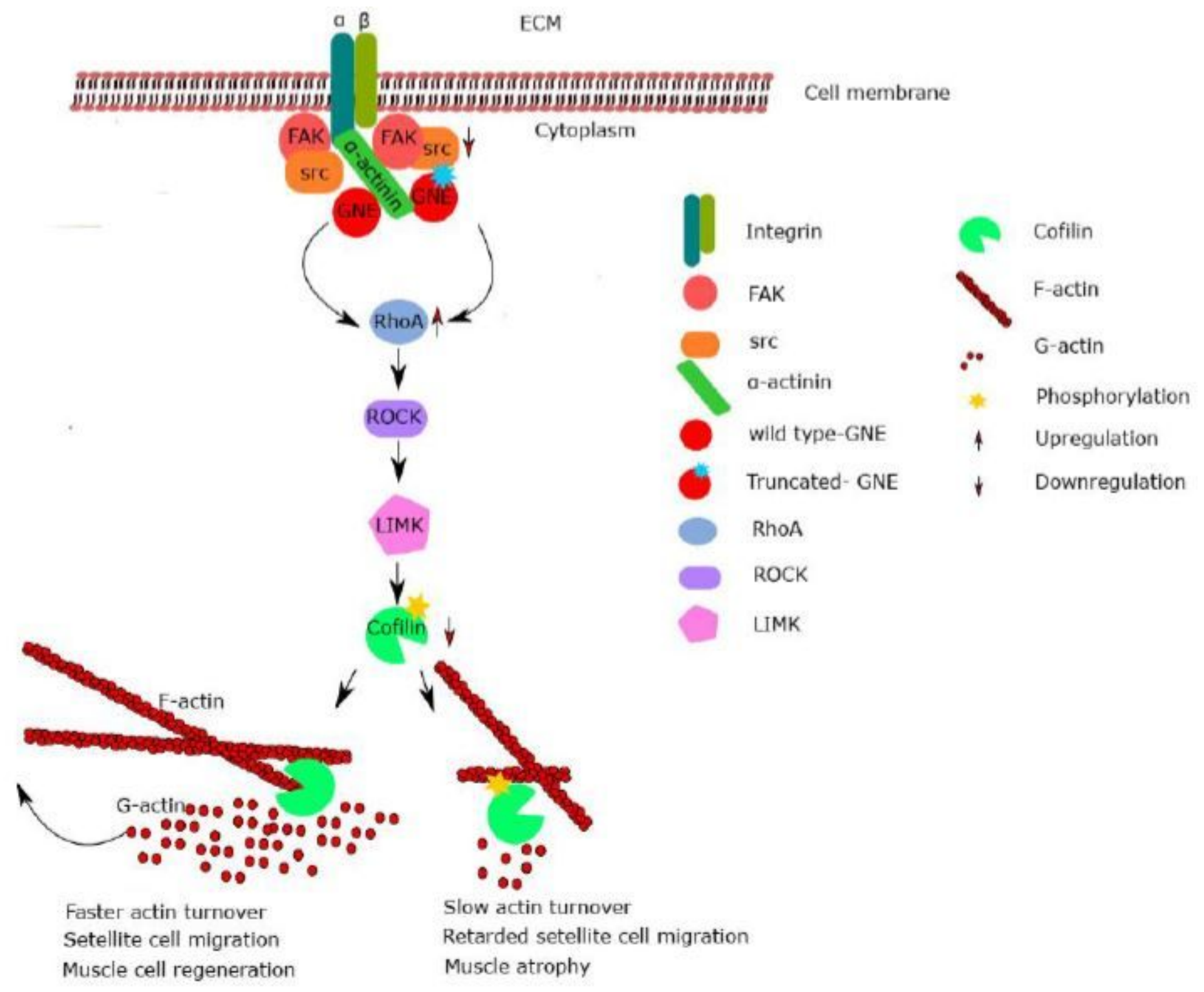

Figure 8

Proposed model. The figure shows that GNE is involved in the regulation of actin dynamics in muscle myoblast cells through RhoA signaling. GNE interacts with a-actinin and associates with focal adhesion complex involving FAK and Src.Under normal conditions GNE association with focal adhesion assembly in response to integrin signaling may activate RhoA that regulatesCofilin function as actin severing protein via phosphorylation. The turnover rate of actin is maintained to provide $\mathrm{G}$-actin monomer and Factin filament. F-actin polymerization occurs that provide force for cell migration. However, when GNE is mutated, it binds more strongly to a-actinin, FAK/Src is downregulated leading to RhoA activation which in turn phosphorylates Cofilin. Increased Cofilin phosphorylation hampers F-actin depolymerization disturbing actin dynamic pool and generation of G-actin monomer. This slow turnover rate of actin reduces cell migration phenomenon. It may have consequenceto reduced muscle cell regeneration.

\section{Supplementary Files}


This is a list of supplementary files associated with this preprint. Click to download.

- supplementaryfile.docx 